\title{
THE ROLE OF ORIENTATION ON THE SHOCK RESPONSE OF SINGLE CRYSTAL
} TANTALUM.

\author{
J. C. F. Millett ${ }^{1 *}$, P. Avraam ${ }^{1}$, G. Whiteman ${ }^{1}$, D. J. Chapman ${ }^{2,3}$, and S. Case ${ }^{1}$. \\ ${ }^{1}$ AWE, Aldermaston, Reading, RG7 4PR. United Kingdom. \\ ${ }^{2}$ Institute of Shock Physics, Blackett Laboratory, Imperial College London. SW7 2AZ, \\ United Kingdom. \\ ${ }^{3}$ Solid Mechanics and Materials Engineering, Department of Engineering Science, University \\ of Oxford, Oxford, OX5 1PF. United Kingdom. \\ *Corresponding email - Jeremy.millett@awe.co.uk
}

PAC.S 62.50

\begin{abstract}
The response of single crystalline tantalum to one dimensional shock loading has been investigated as a function of crystalline orientation to the loading axis. Results show that this has a significant effect, particularly on the Hugoniot Elastic Limit (HEL). The [100] and [111] HELs are near identical with the [110] having the lowest strength. This is contrary to predictions obtained by applying Schmid factor analysis, where the ordering was expected (highest strength first) [111], [110] with the [100] orientation being the softest. Adopting a more appropriate model based on uniaxial strain conditions, as was previously done successfully for FCC aluminium and copper, did not rationalise our observations. We show that a non-Schmid effective stress model, incorporating twinning/anti-twinning asymmetry has much greater success in reproducing the experimental relative HELs magnitudes. Using this model, we make a quantitative estimation of the magnitude of non-Schmid effects, and compare these to equivalent low temperature, quasi-static estimates from the literature.
\end{abstract}




\section{INTRODUCTION}

Interest in the shock response in tantalum is driven from a number of sources. As a high density, ductile metal, it is ideally suited to the manufacture of explosively formed projectiles. In addition, it is also stable in the body centred cubic (BCC) phase up to high pressures, making it a useful candidate for the determination of behaviour under shock loading conditions. As such it, along with other BCC metals, displays properties that distinguish them from the more familiar face centred cubic (FCC) metals (e.g. copper and aluminium). These include a strong strain-rate and temperature dependence of yield strength, usually explained by thermal activation over a large Peierls barrier ${ }^{1}$, the dominance of screw over edge dislocations ${ }^{2}$, violation of the Schmid law that predicts slip on the systems with the highest resolved shear stress $^{3,4}$ and uncertainty concerning operative slip systems ${ }^{5}$. In a recent paper, Lloyd et $a l^{6}$. demonstrated that single crystal effects have an important role to play in influencing the macroscopic response of polycrystalline materials. The data generated from the mechanical testing of single crystals can therefore be very useful for the development of crystal plasticity models that may be used to model realistic (textured) polycrystals.

In BCC crystals, the primary slip direction is of type $\mathrm{a} / 2<111>$ (corner to body centre). The main slip plane is generally $\{110\}$, but slip on $\{112\},\{123\}$ and along planes that are not low index crystallographic planes has also been observed ${ }^{7}$. Shears in the positive and negative directions along $<111>$ are only equivalent on the $\{110\}$ planes $^{8}$. For a general plane that is not $\{110\}$, the critical resolved shear stress (CRSS) varies with respect to the sense of shear resolved in the slip direction of that plane (a manifestation of the so-called twinning/antitwinning - T/AT - asymmetry). This asymmetry is related to the way the dislocation core structure and energetics change when they are driven on those planes. The CRSS is greater for shear in the anti-twinning sense, thus violating the Schmid law. Non-glide stresses (that is components of the applied shear stress that are perpendicular to the slip directions, and therefore 
do not give rise to a Peach-Koehler force on the dislocation) can also distort the dislocation core structure, which ultimately affects the CRSS. These effects are thought to be the major contributing factor in the tension/compression asymmetry observed in BCC materials ${ }^{9}$.

There exists a level of ambiguity concerning the active slip planes in BCC metals ${ }^{10-15}$. Some studies suggest the slip is confined to the $\{112\}$ and $\{123\}$ planes whilst others indicate that slip on $\{110\}$ and $\{112\}$ operate at low temperatures, with $\{123\}$ becoming active at high temperatures. While edge and mixed character dislocations are confined to well defined slip planes, screw dislocations do not have defined slip planes. It is thought that slip in BCCs is mediated predominately though the motion of crew dislocations and it has been suggested that the apparent slip on $\{112\}$ and $\{123\}$ really consists of composite motion of screw dislocations on alternating $\{110\}$ planes. Other studies indicate that pencil glide (where slip occurs on the plane coinciding with the maximum resolved shear stress - MRSS) is operative. Atomistic studies generally predict that screw dislocation motion occurs in fundamental steps along $\{110\}$ planes, but that steps on $\{112\}$ planes can occur by composite motion on alternate $\{110\}$ planes ${ }^{11}$. Most atomistic studies predict composite steps on the $\{112\}$ planes $^{4}$. These results are subject to the usual note of caution regarding the potential accuracy of classical interatomic potentials. Molecular dynamics simulation on $\mathrm{BCC}$ iron ${ }^{16}$ has shown that the average motion of screw dislocations can proceed on arbitrary non-crystallographic planes, with the precise trajectory depending on the stress and temperature.

Low strain-rate compression and tension experiments on single crystal tantalum ${ }^{3,10,13,14}$ reveal non-Schmid effects, tension-compression asymmetry, strong directionality of the yield stress and sensitivity to impurity content. Christian ${ }^{8}$ notes that many of the non-Schmid effects are explained, at least qualitatively by assuming that resistance to glide on the $\{112\}$ planes is lower in the twinning sense than the anti-twinning sense. Microstructural analyses on single 
crystals deformed along $[110]^{14}$ revealed localised rotations within the crystal due to plastic slip, but no evidence of other deformation mechanisms such as twinning.

At higher strain-rates (of the order $10^{3} \mathrm{~s}^{-1}$ ), split Hopkinson pressure bar (SHPB) techniques have been used to load [100] and [110] ${ }^{17}$ and [149] and [144] ${ }^{18}$ directions over a range of temperatures. A strong dependence of yield stress and strain hardening on crystal direction was seen. Single crystals deformed along [110] under uniaxial stress conditions at both quasi-static ${ }^{19}$ and $\mathrm{SHPB}^{17}$ induced strain-rates show essentially plane strain that endures to large strains, with initially cylindrical samples developing an ovoid cross-section. In recent studies, single crystal tantalum was deformed along different crystallographic directions, using quasi-static deformation ${ }^{20}$ and Taylor impact ${ }^{21}$, and modelled using crystal plasticity finite element modelling. They found evidence of slip on $\{211\}$ as the dominant deformation mechanism, even when non-Schmid effects were considered.

Increasing the strain-rate further $\left(10^{5}-10^{7} \mathrm{~s}^{-1}\right)$, quasi-isentropic loading experiments have been performed on the [100] and [110] directions to pressures of 18 and $86 \mathrm{GPa}^{22}$. Strong orientation dependence of both the elastic-plastic response and the ramp elastic limit (REL) were observed. Simulations of these experiments ${ }^{23}$ considered operative slip systems of type $\{110\}<111>$ and $\{112\}<111>$, incorporating evolution of the mobile dislocation density. Modelling anisotropy in dislocation nucleation rates associated with the T/AT asymmetry was found to be key in describing the relative REL magnitudes in different crystal directions.

Our own one dimensional shock (plate impact) experiments on [100], [110] and [111] tantalum single crystals ${ }^{24}$ have measured free surface wave profiles at impact stresses of 6 and $23 \mathrm{GPa}$. Variations in elastic limits and low stress shock velocities were observed, particularly for the [100] and [111] orientations, while the [110] behaviour appeared most similar to polycrystalline tantalum. Single crystals have been recovered for post shock microstructural analysis $^{25,26}$ in the [100], [110], [111] and [123] orientations at pressures between 25 and 55 
GPa. Very small twin fractions were observed at $25 \mathrm{GPa}$ in the three principal directions with a more sizeable fraction in [123]. At $55 \mathrm{GPa}$, little twinning was observed in [100], more in [111] and a large fraction in [123].

Shock pressures of between 10 and $110 \mathrm{GPa}$ have been imposed on tantalum single crystals via laser driven experiments ${ }^{27}$ on [100] and [111] orientations. As the imposed shocks were unsupported or decaying, different parts of the crystals experienced different pressures. Microstructual analysis of the recovered crystals showed significant levels of residual dislocations (mostly of screw character) and twins (generally of type $\{112\}<111>$ ) in regions that experienced shocks above $40 \mathrm{GPa}$. As the shock amplitude decayed, the incidence of twinning dropped markedly, as did the residual dislocation density. Evidence of a BCC to hexagonal close packed (HCP) phase transformation was also presented at stresses of $68 \mathrm{GPa}$ and above.

The work discussed in this report is part of a much wider study on tantalum, including the effects of cold work ${ }^{28}$ and alloy additions ${ }^{29}$ on the shock response, microstructural development in shocked single crystals (without momentum trapping to prevent lateral release) and effects of orientation on yielding of single crystals ${ }^{24,30}$. In addition, we have also studied the effects of orientation on the shock response of single crystal aluminium, both from in-situ mechanical response $\mathrm{e}^{31}$ and post-shock mechanical properties ${ }^{32}$. In this paper, we extend the work previously reported by increasing both the pressure range and thicknesses of the samples.

\section{EXPERIMENTAL}

A series of eight plate impact experiments were performed using the single stage gas launchers, based at AWE and Imperial College London $(70 \mathrm{~mm}$ and $100 \mathrm{~mm}$ diameter bores respectively). Each target assembly consisted of three single tantalum crystals (one of each principal orientation). Two separate geometries were tested; type 1 were mounted into an 
aluminium alloy ring, along with one $35 \mathrm{~mm}$ diameter polycrystalline tantalum disk. Sample thicknesses were of the order $4 \mathrm{~mm}$. The samples were potted into the aluminium ring using a slow setting epoxy resin. Impact stresses were generated by the impact of $c a .3 \mathrm{~mm}$ thick tantalum flyers. Type 2 targets consisted of just the three single crystals mounted onto the rear of either z-cut quartz or sapphire cover plates, with the flyer matched to the material of the cover plate. The sample thicknesses were either 0.8 or $4 \mathrm{~mm}$. In both sample geometries, the principal diagnostic was heterodyne Velocimetry (HetV or PDV $)^{33}$, used to measure rear surface velocity of the tantalum samples. One HetV channel, focussed centrally on each sample was used, along with an extra three channels focused on the free surface of the cover plate in the type 2 experiments. A final channel of $\mathrm{HetV}$ was also fielded through the target assembly to measure the velocity of the impactor. In each target type, piezoelectric (lead-zirconium titanate; PZT) pins were mounted co-planar with the front faces of the tantalum samples, to measure impact time and tilt.

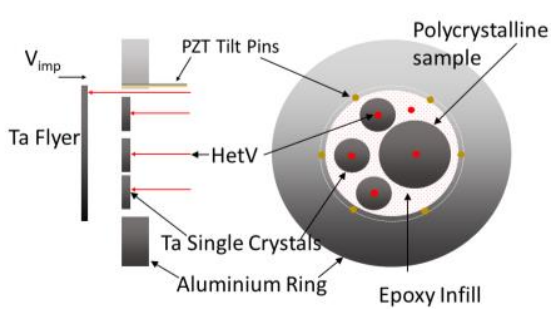

a)

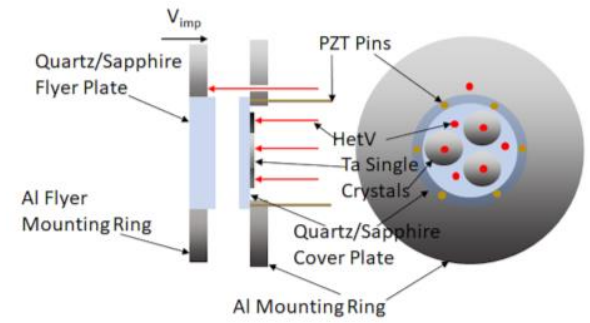

b)

Figure 1: Schematic of target and diagnostic set ups for a) Type 1 geometry and b) Type 2 geometry.

The recorded pin data showed that overall tilt was 1.3 mradians or better for all targets. Schematic diagrams of both target geometries are presented in Figure 1, and a summary of experimental conditions is shown in Table I. 
Table I: Experimental geometry and impact velocities. Errors on measured values are given in parentheses.

\begin{tabular}{|c|c|c|c|c|c|c|c|}
\hline Experiment & $\begin{array}{l}\text { Impactor/ } \\
\text { Cover plate } \\
\text { material }\end{array}$ & $\begin{array}{l}\text { Impact } \\
\text { velocity } \\
\left(\mathrm{mm} \mu \mathrm{s}^{-1}\right)\end{array}$ & $\begin{array}{l}\text { Impactor } \\
\text { thickness } \\
(\mathbf{m m})\end{array}$ & $\begin{array}{l}\text { Cover plate } \\
\text { thickness } \\
(\mathbf{m m})\end{array}$ & $\begin{array}{l}{[100]} \\
\text { thickness } \\
(\mathbf{m m})\end{array}$ & $\begin{array}{l}{[110]} \\
\text { thickness } \\
(\mathbf{m m})\end{array}$ & $\begin{array}{l}{[111]} \\
\text { thickness } \\
(\mathbf{m m})\end{array}$ \\
\hline CSC1-1 & $\begin{array}{l}\text { Polycrystal. } \\
\text { tantalum }\end{array}$ & $\begin{array}{l}212.2 \\
(0.5)\end{array}$ & $\begin{array}{l}2.970 \\
(0.003)\end{array}$ & N/A & $\begin{array}{l}3.999 \\
(0.002)\end{array}$ & $\begin{array}{l}4.019 \\
(0.002)\end{array}$ & $\begin{array}{l}4.022 \\
(0.002)\end{array}$ \\
\hline CSC1-2 & $\begin{array}{l}\text { Polycrystal. } \\
\text { tantalum }\end{array}$ & $\begin{array}{l}197.6 \\
(0.5) \\
\end{array}$ & $\begin{array}{l}.977 \\
(0.003) \\
\end{array}$ & N/A & $\begin{array}{l}4.011 \\
(0.002) \\
\end{array}$ & $\begin{array}{l}4.012 \\
(0.002) \\
\end{array}$ & $\begin{array}{l}4.011 \\
(0.002) \\
\end{array}$ \\
\hline CSC1-3 & $\begin{array}{l}\text { Polycrystal. } \\
\text { tantalum }\end{array}$ & $\begin{array}{l}726.2 \\
(0.5) \\
\end{array}$ & $\begin{array}{l}2.978 \\
(0.003) \\
\end{array}$ & N/A & $\begin{array}{l}4.010 \\
(0.002) \\
\end{array}$ & $\begin{array}{l}4.019 \\
(0.002) \\
\end{array}$ & $\begin{array}{l}4.021 \\
(0.002) \\
\end{array}$ \\
\hline CSC1-4 & $\begin{array}{l}\text { Polycrystal. } \\
\text { tantalum }\end{array}$ & $\begin{array}{l}730.8 \\
(0.5) \\
\end{array}$ & $\begin{array}{l}3.020 \\
(0.003) \\
\end{array}$ & N/A & $\begin{array}{l}4.008 \\
(0.002) \\
\end{array}$ & $\begin{array}{l}4.024 \\
(0.002) \\
\end{array}$ & $\begin{array}{l}4.024 \\
(0.002) \\
\end{array}$ \\
\hline CSC2-1 & $\begin{array}{l}\text { Z-cut } \\
\text { sapphire }\end{array}$ & $\begin{array}{l}567.1 \\
(0.5)\end{array}$ & $\begin{array}{l}10.082 \\
(0.002)\end{array}$ & $\begin{array}{l}5.980 \\
(0.002)\end{array}$ & $\begin{array}{l}3.997 \\
(0.002)\end{array}$ & $\begin{array}{l}4.026 \\
(0.002)\end{array}$ & $\begin{array}{l}4.026 \\
(0.002)\end{array}$ \\
\hline CSC2-2 & Z-cut quartz & $\begin{array}{l}430.0 \\
(3.0) \\
\end{array}$ & $\begin{array}{l}10.041 \\
(0.001) \\
\end{array}$ & $\begin{array}{l}6.067 \\
(0.002) \\
\end{array}$ & $\begin{array}{l}0.824 \\
(0.02) \\
\end{array}$ & $\begin{array}{l}0.793 \\
(0.02) \\
\end{array}$ & $\begin{array}{l}0.839 \\
(0.02) \\
\end{array}$ \\
\hline CSC2-3 & Z-cut quartz & $\begin{array}{l}290.6 \\
(0.5)\end{array}$ & $\begin{array}{l}10.087 \\
(0.001)\end{array}$ & $\begin{array}{l}6.034 \\
(0.002)\end{array}$ & $\begin{array}{l}4.001 \\
(0.002)\end{array}$ & $\begin{array}{l}4.026 \\
(0.002)\end{array}$ & $\begin{array}{l}4.025 \\
(0.002)\end{array}$ \\
\hline CSC2-4 & $\begin{array}{l}\text { Z-cut } \\
\text { sapphire }\end{array}$ & $\begin{array}{l}567.6 \\
(0.5) \\
\end{array}$ & $\begin{array}{l}10.073 \\
(0.002) \\
\end{array}$ & $\begin{array}{l}5.987 \\
(0.002) \\
\end{array}$ & $\begin{array}{l}0.756 \\
(0.005) \\
\end{array}$ & $\begin{array}{l}0.729 \\
(0.005) \\
\end{array}$ & $\begin{array}{l}0.839 \\
(0.001) \\
\end{array}$ \\
\hline
\end{tabular}

\section{MATERIALS}

Three bars (diameter $c a .14 \mathrm{~mm}$ ) of single crystal tantalum were purchased from Metal Crystals and Oxides, Ltd, Cambridge, UK. The bars were grown with axes parallel to the three principal ([100], [110] and [111]) crystallographic directions, with reported mis-orientations of the order $0.5^{\circ}$ and a purity of $99.99 \%$ minimum. Transmission electron microscopy (TEM) images of the undeformed crystals are shown in Figure 2. All three orientations show low dislocation densities (measured to be $c a .6 \times 10^{12} \mathrm{~m}^{-2}$ ) in each sample. No evidence of low angle boundaries was observed. Measured interstitial solute contents are presented in Table II.

Table II: Measured mean interstitial content and standard errors (SE) for tantalum single crystal samples in parts per million (ppm).

\begin{tabular}{|l|l|l|l|l|l|l|}
\hline \multirow{2}{*}{ Sample } & \multicolumn{2}{|c|}{ Carbon } & \multicolumn{2}{c|}{ Oxygen } & \multicolumn{2}{c|}{ Nitrogen } \\
\cline { 2 - 7 } & $\begin{array}{l}\text { Mean } \\
(\mathrm{ppm})\end{array}$ & $\begin{array}{l}\text { SE } \\
(\mathrm{ppm})\end{array}$ & $\begin{array}{l}\text { Mean } \\
(\mathrm{ppm})\end{array}$ & $\begin{array}{l}\text { SE } \\
(\mathrm{ppm})\end{array}$ & $\begin{array}{l}\text { Mean } \\
(\mathrm{ppm})\end{array}$ & $\begin{array}{l}\text { SE } \\
(\mathrm{ppm})\end{array}$ \\
\hline$[\mathbf{1 0 0}]$ & 50 & 7 & 130 & 19 & 22 & 6 \\
\hline$[\mathbf{1 1 0}]$ & $55^{*}$ & -- & 180 & 8 & $<20$ & -- \\
\hline$[111]$ & 55 & 5 & 130 & 11 & 32 & 11 \\
\hline Polyxtal $^{+}$ & 16 & & 30 & & 20 & \\
\hline
\end{tabular}


Longitudinal and shear sound speeds ( $c_{\mathrm{L}}$ and $c_{\mathrm{S}}$ respectively) were measured at ambient temperature and pressure using pulse echo techniques, with density $\left(\rho_{0}\right)$ measured via pycnometry. The results are presented in Table III.

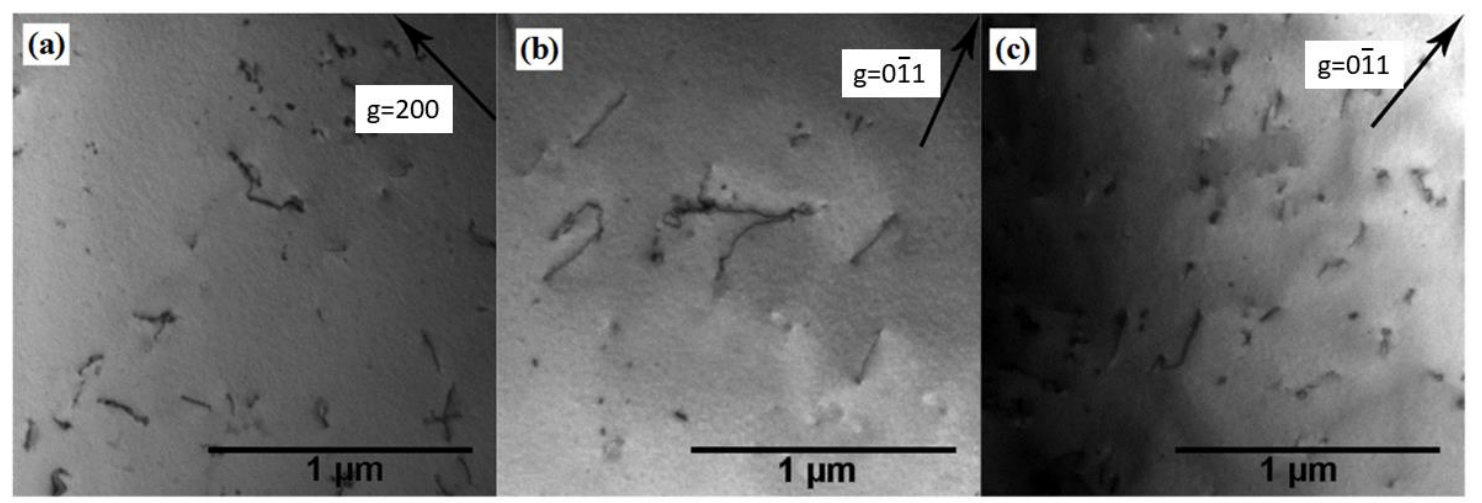

Figure 2. TEM images of the initial single crystal tantalum sample; a) [100], b [110] and c) [111]. $\mathrm{g}$ is the reciprocal lattice vector of the lattice plane giving rise to reflection.

Table III: Measured sound speeds and densities for tantalum crystals. Errors on measured values are given in parentheses. Values in italics are calculated from the measured elastic constants of Bolef $^{34}$.

\begin{tabular}{|c|l|l|l|}
\hline Sample & \multicolumn{1}{|c|}{$\boldsymbol{c}_{\mathbf{L}}\left(\mathbf{m m} \boldsymbol{\mu} \mathbf{s}^{\mathbf{- 1}}\right)$} & \multicolumn{1}{c|}{$\boldsymbol{c}_{\mathbf{S}}\left(\mathbf{m m} \boldsymbol{\mu s}^{-\mathbf{1}}\right)$} & \multicolumn{1}{c|}{$\boldsymbol{\rho}_{\mathbf{0}}\left(\mathbf{g ~ c m}^{-\mathbf{3}}\right)$} \\
\hline$[\mathbf{1 0 0}]$ & $4.02(0.03) ; 4.01$ & $2.23(0.02) ; 2.23$ & $16.58(0.01)$ \\
\hline$[\mathbf{1 1 0}]$ & $4.24(0.02) ; 4.23$ & $2.24(0.01) ; 2.23$ & $16.58(0.01)$ \\
\hline$[\mathbf{1 1 1}]$ & $4.30(0.02) ; 4.29$ & $1.78(0.01) ; 1.79$ & \\
\hline Polyxtal & $4.17(0.02)$ & $1.94(0.02) ; 1.94$ & $16.61(0.01)$ \\
\hline
\end{tabular}

The two measurements given for the shear velocity in the [110] crystal, measured as the transducer was rotated, are due to the distinction between the effective elastic constants for the two transverse modes for this orientation in a cubic material. We have also included values calculated from the known elastic constants $\left(C_{11}=267 \mathrm{GPa}, C_{12}=161 \mathrm{GPa}\right.$ and $\left.C_{44}=82.5 \mathrm{GPa}\right)$ determined by Bolef ${ }^{34}$. 


\section{RESULTS}

In Figure 3 we present simultaneous traces taken from crystals of thickness $c a .4 \mathrm{~mm}$ at impact stresses from 4 to $23 \mathrm{GPa}$, including a polycrystalline specimen (see Fig. 1a).

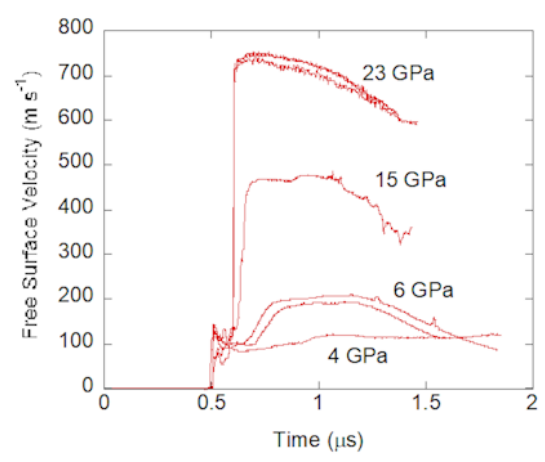

a) $[100]$

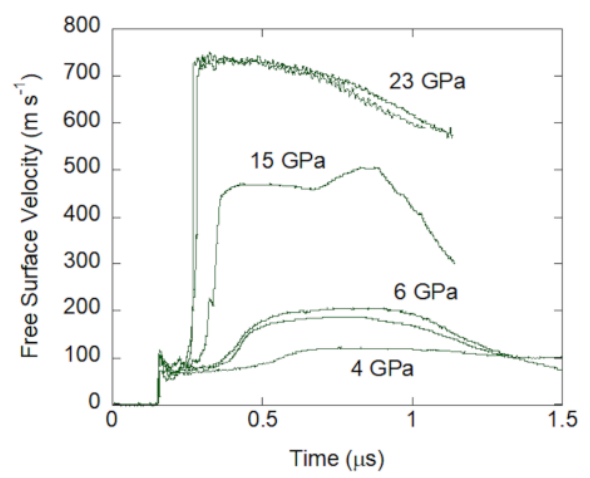

c) $[111]$

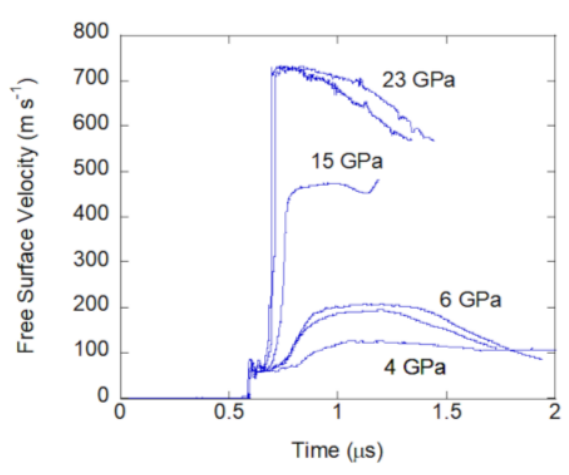

b) $[110]$

Figure 3. Free surface measurements from $4 \mathrm{~mm}$ crystals, impacted from 4 to $23 \mathrm{GPa}$. a) [100] orientation, b) [110] orientation and c) [111] orientation. Note that the traces at 6 and $23 \mathrm{GPa}$ have been repeated (shots CSC1-1 and 2, and CSC1-3 and 4 respectively - see Table I).

The basic features of the traces consist of a rapid rise in velocity to an initial step, followed by a slower rise in velocity taking the material to its final state. Like in many metallic materials, 
we are associating this first step with the transition between elastic and plastic deformation. Generally, this is known as the Hugoniot Elastic Limit (HEL); the one-dimensional strain equivalent of the yield stress. However, we feel it necessary to introduce a note of caution in using this term. The term HEL implies that the elastic behaviour of the material has reached a steady value during shock loading. However, in tantalum, like many other materials, this stress decreases with specimen thickness until a final steady level is reached. In a previous paper ${ }^{28}$, we showed that in polycrystalline tantalum, this could be of the order of several $\mathrm{mm}$. Given that in this investigation, specimen thicknesses are either $0.8 \mathrm{~mm}$ or $4 \mathrm{~mm}$, we consider it unlikely that a steady stress state is reached, especially in the thinner specimens. However, for the sake of simplicity, we will continue to refer to the transition between elastic and plastic behaviour as the HEL, whilst acknowledging that this not strictly the case. The characteristics of the HEL - the overshoot and lower value are fairly typical of BCC metals under shock loading, and has been observed previously in polycrystalline tantalum ${ }^{25,28}$ as well as ramp loading experiments ${ }^{22}$ and is reminiscent of the upper and lower yield points demonstrated at quasi-static strain-rates by BCC metals and alloys (including tantalum $)^{7}$. Such behaviour has been explained in terms of the kinetics of mobile dislocation density evolution, the low initial availability of mobile dislocations, and the initial resistance to dislocation motion. In a previous $\operatorname{paper}^{28}$, we suggested that this was due to interstitial oxygen atoms pinning dislocations in place until a sufficiently high stress was imposed to displace them. In that work, we noted that after a $50 \%$ reduction in thickness by cold rolling, the upper and lower HELs were replaced by a single, more diffuse yield point. This was used to justify the previous hypothesis by suggesting that prior cold deformation could remove dislocations from the pinning interstitials, thus lowering the HEL. Similar results have also been observed, both under shock and ramp loading conditions ${ }^{22,25}$. Note that the content (particularly oxygen) is significantly higher in the single crystals when compared to the polycrystalline material (see Table II). 


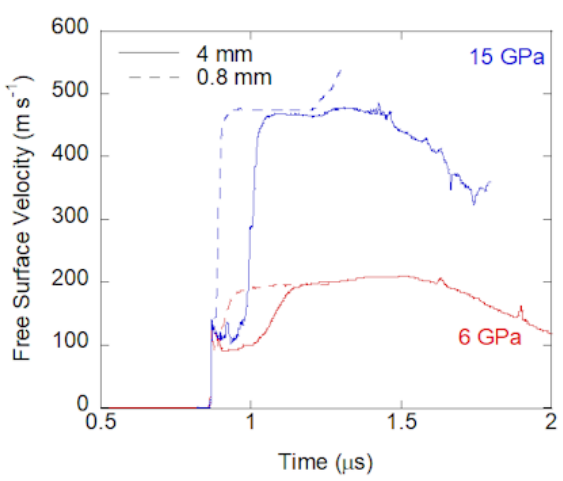

a) [100]

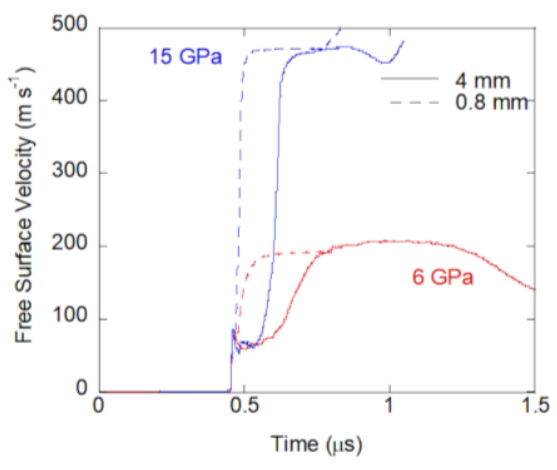

b) $[110]$

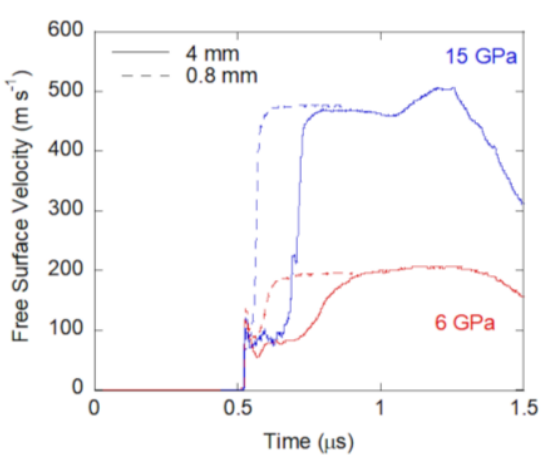

c) $[111]$

Figure 4. Free surface velocities of single crystal tantalum for crystal thicknesses of 0.8 and 4 mm. a) [100] orientation, b) [110] orientation and c) [111] orientation.

Similar behaviour can be observed in Figure 4, where we examine the effects of specimen thickness. In the case of many of the traces from $0.8 \mathrm{~mm}$ thick samples, a reload can be seen towards the end of the signal. This is due to the release from the free surface of the targets reflecting at the interface of the crystal/cover plate. Given that the cover plate is manufactured from either sapphire or quartz (both lower in impedance than tantalum) the reflection back from this interface will be compressive in nature, resulting in the observed reload.

One final feature worthy of mention is evidence of a small jog on the plastic rise part some of the velocity time traces. It is most noticeable on the [110] and [111] traces (see Figs. 3 b and c and Fig. 4c), but can also be observed on some of the [100] traces (Fig. 4a). Such features have been observed in other materials, for example Ti- $6 \mathrm{Al}-4 \mathrm{~V}^{35}$, and the most likely 
explanation is that this is the result of a partial elastic reflection from the oncoming plastic shock front.

Hugoniot data for single crystal tantalum, in both $U_{\mathrm{S}}$ (shock velocity) - $\left(u_{\mathrm{p}}\right)$ particle velocity and $P_{\mathrm{HD}}$ (hydrodynamic pressure) $-u_{\mathrm{p}}$ space are presented in Figure 5 . The fitted curve assumes the standard shock relations,

$$
U_{S}=c_{0}+S u_{p} \text { and } P_{H D}=\rho_{0} U_{S} u_{p}
$$

where $c_{0}$ and $S$ (the empirical shock parameters) have quoted values of $3.43 \mathrm{~mm} \mathrm{\mu s}^{-1}$ and 1.19 from $\mathrm{Marsh}^{36}$. For comparison, we have also included literature data for polycrystalline tantalum, both from Furnish $e t a l^{37}$. and ourselves from a previous investigation ${ }^{28}$. In common with the data from that publication, we have used the longitudinal elastic wave speed $\left.c_{\mathrm{L}}\right)$, carrying deformation up to the elastic limit as a fiducial, and used the timing of the plastic part of the shock front half way between the elastic limit and peak free surface velocity to calculate the shock velocity via,

$U_{S}=\frac{d}{\frac{d}{c_{L}}+\Delta t}$,

where $d$ is the specimen thickness and $\Delta t$ is the time difference between the arrival of the elastic and plastic parts of the shock.

Above a particle velocity of $c a .0 .1 \mathrm{~mm} \mathrm{\mu s}^{-1}$, the response of all three crystals is close to linear as might be expected with a simple metal such as tantalum, although it is clear that there is a strong dependency on orientation; the response of the [110] and [111] orientations appear close to that of the polycrystalline material, with [100] lying noticeably lower. This is apparently in agreement with the lower sound velocities in [100] (in comparison to both other 


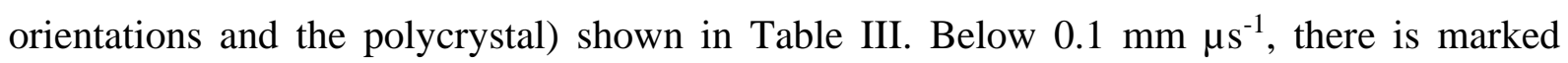
deviation to lower shock velocities away from the standard linear response, both in our single crystals and the quoted polycrystalline data ${ }^{37}$. We have also noted a similar response in molybdenum ${ }^{38}$, and this is most likely an indication of the instability of the shock wave at these low stresses.

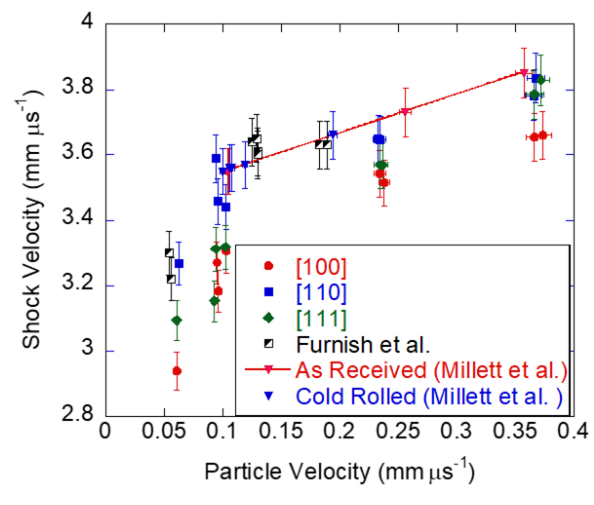

a) Shock velocity - particle velocity

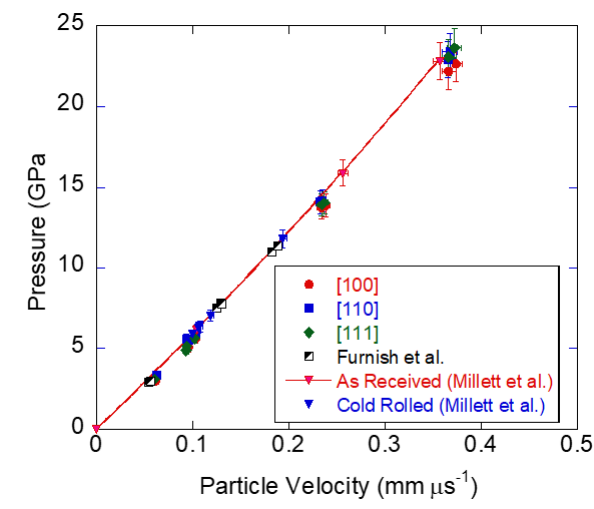

b) Pressure - particle velocity

Figure 5. The shock Hugoniot of tantalum as a function of crystal orientation to the loading axis. a) shock velocity versus particle velocity and b) pressure versus particle velocity. Data from the polycrystalline work of both Furnish et $a l^{37}$. and ourselves ${ }^{28}$ from a previous publication are included for comparison. The solid red lines are based on the relation from $\operatorname{Marsh}^{36}-U_{\mathrm{S}}=3.43+1.19 u_{\mathrm{p}}$.

In Figure 6 and Table IV, we present the Elastic Limit data (yield under conditions for one dimensional strain during shock loading) for all three orientations, as a function of specimen thickness. These have been calculated using the free surface velocities at the break in slope in the free surface velocity traces in Figs 3 and $4\left(u_{\mathrm{fse}}\right)$, where,

$\sigma_{H E L}=\rho_{0} c_{L} \frac{u_{f s e}}{2}$ 
$\rho_{0}$ is the appropriate ambient density and $c_{\mathrm{L}}$ is the appropriate longitudinal sound speed (see Table III). We have not included the data for the peak elastic stress in the plot (although it is presented in Table IV) since the fast rising nature of this part of the signal may be beyond the resolution of both the HetV techniques and the subsequent analysis. Therefore we cannot be confident that the derived peak values would be accurate. Also included are the data obtained from ramp loading experiments from Asay $e t a l^{22}$. for comparison.

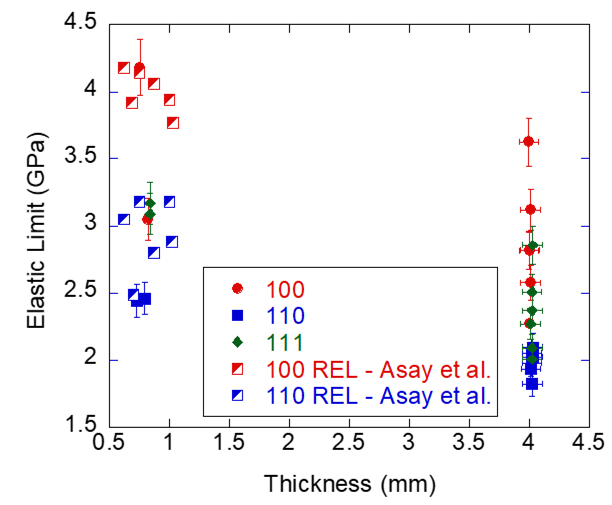

Figure 6. Variation of the Hugoniot Elastic Limit with crystal orientation to the loading axis.

Table IV. Summary of elastic precursor amplitude measurements.

\begin{tabular}{|l|l|l|l|l|l|}
\hline Experiment & $\begin{array}{l}\text { Thickness } \\
(\mathrm{mm})\end{array}$ & $\begin{array}{l}\text { HEL Peak } \\
\text { Velocity }\left(\mathrm{m} \mathrm{s}^{-1}\right)\end{array}$ & $\begin{array}{l}\text { HEL Minimum } \\
\text { Velocity }\left(\mathrm{m} \mathrm{s}^{-1}\right)\end{array}$ & $\begin{array}{l}\text { Peak } \\
\text { Elastic } \\
(\mathrm{GPa})\end{array}$ & $\begin{array}{l}\text { Minimum } \\
\text { Elastic (GPa) }\end{array}$ \\
\hline CSC1-1 [100] & 3.999 & 0.126 & 0.085 & 4.209 & 2.816 \\
\hline CSC1-1 [110] & 4.019 & 0.078 & 0.056 & 2.749 & 1.975 \\
\hline CSC1-1 [111] & 4.022 & 0.118 & 0.070 & 4.200 & 2.511 \\
\hline CSC1-2 [100] & 4.011 & 0.142 & 0.094 & 4.739 & 3.119 \\
\hline CSC1-2 [110] & 4.012 & 0.080 & 0.055 & 2.794 & 1.933 \\
\hline CSC1-2 [111] & 4.011 & 0.098 & 0.064 & 3.500 & 2.268 \\
\hline CSC1-3 [100] & 4.010 & 0.092 & 0.077 & 3.049 & 2.579 \\
\hline CSC1-3 [110] & 4.019 & 0.071 & 0.058 & 2.489 & 2.053 \\
\hline
\end{tabular}




\begin{tabular}{|l|l|l|l|l|l|}
\hline CSC1-3 [111] & 4.021 & 0.104 & 0.056 & 3.721 & 2.007 \\
\hline CSC1-4 [100] & 4.008 & 0.079 & 0.068 & 2.643 & 2.270 \\
\hline CSC1-4 [110] & 4.024 & 0.082 & 0.052 & 2.893 & 1.821 \\
\hline CSC1-4 [111] & 4.024 & 0.074 & 0.059 & 2.625 & 2.093 \\
\hline CSC2-1 [100] & 3.997 & 0.138 & 0.109 & 4.592 & 3.626 \\
\hline CSC2-1 [110] & 4.026 & 0.084 & 0.057 & 2.960 & 2.095 \\
\hline CSC2-1 [111] & 4.026 & 0.103 & 0.080 & 3.693 & 2.857 \\
\hline CSC2-2 [100] & 0.824 & 0.117 & 0.092 & 3.896 & 3.049 \\
\hline CSC2-2 [110] & 0.793 & 0.083 & 0.070 & 2.910 & 2.461 \\
\hline CSC2-2 [111] & 0.839 & 0.135 & 0.087 & 4.832 & 3.089 \\
\hline CSC2-3 [100] & 4.001 & 0.120 & 0.085 & 3.999 & 2.819 \\
\hline CSC2-3 [110] & 4.026 & 0.086 & 0.058 & 3.030 & 2.021 \\
\hline CSC2-3 [111] & 4.025 & 0.106 & 0.066 & 3.785 & 2.368 \\
\hline CSC2-4 [100] & 0.756 & 0.146 & 0.126 & 4.849 & 4.182 \\
\hline CSC2-4 [110] & 0.729 & 0.086 & 0.069 & 3.033 & 2.439 \\
\hline CSC2-4 [111] & 0.839 & 0.118 & 0.089 & 4.210 & 3.168 \\
\hline & & & & & \\
\hline
\end{tabular}

Although there is a degree of scatter, a number of trends can be identified. Firstly, it would appear that the [100] orientation has the highest strength, followed by [111], with [110] having the lowest. The stress levels would also appear to be consistent with the REL (Ramped Elastic Limit) data from the [100] and [110] orientations from Asay et $a l^{22}$. However, we note with interest that the ordering of the [100] and [111] orientations are reversed when compared to one dimensional stress measurements. This may be an indication that the strain-rate sensitivity is orientation dependent.

\section{DISCUSSION}

The data presented in this paper shows that the response of single crystal tantalum under shock loading conditions is strongly influenced by the orientation of the crystal to the loading 
axis, both in terms of the equation of state (the Hugoniot) and the mechanical response (HEL). Looking at the Hugoniot data first, it can be seen from Fig. 5a that above a particle velocity of

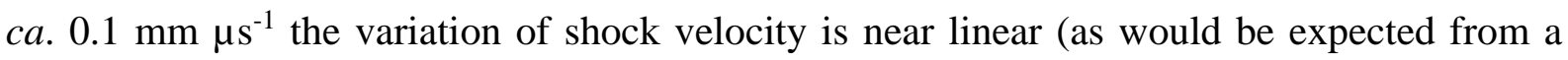
simple metal) and in the case of the [110] and [111] orientations, in reasonable agreement with data presented from studies on polycrystalline material, with the [100] data lying slightly below. The most likely explanation is that the lower sound speeds (particularly the longitudinal sound speed) in the [100] orientated crystal (see Table III) are responsible. Note that in all cases (single crystal and polycrystal) below $0.1 \mathrm{~mm} \mu \mathrm{s}^{-1}$, there is a significant drop off in shock velocity below the linear response of Marsh $^{36}$. Furnish $e a^{37}$. suggested that this maybe an indication of material anisotropy (perhaps not surprising in a single crystal), but Fiske $e t a l^{39}$. indicated that this may more likely be a wave stability issue affecting accuracy in measuring the shock velocity. From Fig. 3, the traces from all three orientations when shocked to 4 GPa show that the peak stress is only fractionally greater than the peak elastic stress. The result of this is that the gradient of the plastic part of the loading pulse is shallow, making identification of the shock velocity extremely difficult. We examine the issues of wave stability further in Figure 8, where we compare shock traces for all three orientations, as a function of specimen thickness. To do so, we have normalised the time axis by dividing by the relevant specimen thickness.

Under steady shock conditions, it would be expected that normalised traces would lie one on top of the other. In the case of the $6 \mathrm{GPa}$ traces (Figure 7a.), this is clearly not the case, thus indicating that at least at a specimen thickness of $c a .0 .8 \mathrm{~mm}$, the shock is not steady. Increasing stress to ca. $15 \mathrm{GPa}$ improves matters significantly, but it can still be seen that there is some (small) difference between the traces. 


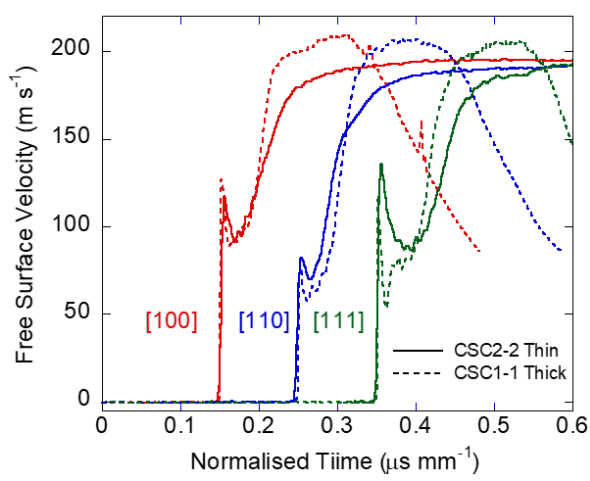

a) $6 \mathrm{GPa}$

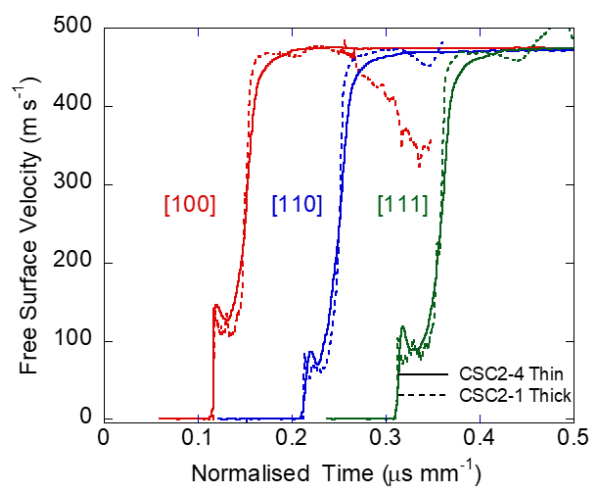

b) $15 \mathrm{GPa}$

Figure 7. Comparison of thickness normalised traces (Thin $-c a .0 .8 \mathrm{~mm}$ and Thick $-c a .4$ $\mathrm{mm})$. a) lower pressure shots at $6 \mathrm{GPa}, \mathrm{b}$ ) high pressure shot at $15 \mathrm{GPa}$.

The results presented in Fig. 6 demonstrate that despite a degree of scatter, the HEL of single crystal tantalum is dependent on the loading axis, with the [100] and [111] orientations being near equal, and the [110] orientation showing the lowest strength. The traditional method to identify the cause is to calculate the critically resolved shear stress ( $\left.\tau_{\mathrm{CRSS}}\right)$ through the Schmid factor, $M$,

$\tau_{C R S S}=\cos \theta \cos \lambda \sigma=M \sigma$

4.

where $\sigma$ is the applied stress, $\theta$ is the angle between the slip plane normal and the loading axis and $\lambda$ is the angle between the slip direction and the loading axis. Slip should occur along the system with the highest value of $M$, which is maximised when $\theta$ and $\lambda$ are both at $45^{\circ}$ to the loading axis $(M=0.5)$. In general, metals prefer to slip on planes and in directions with the closest packing. In the case of BCC metals (such as tantalum), the closest packed direction is 
[111] with three planes, $\{110\},\{112\}$ and $\{123\}$ of equal packing density. Slip on $\{123\}$ tends to only occur at higher temperatures ${ }^{7}$ (above half the absolute melting temperature), so we have concentrated on the $\{110\}$ and $\{112\}$ based systems. The Schmid factors for each orientation on each available slip system have been calculated and are presented in Table V.

Table V. Schmid factors for the three loading axes for both the $\{110\}[111]$ and $\{112\}[111]$ slip systems.

\begin{tabular}{|c|c|c|c|c|}
\hline Slip Plane & Slip Direction & $M[100]$ & $M[110]$ & $M[111]$ \\
\hline 110 & $\overline{1} 11$ & -0.408 & 0 & 0.272 \\
\hline 110 & $1 \overline{11} 1$ & 0.408 & 0 & 0.272 \\
\hline 011 & $\overline{\mathbf{1} 11}$ & 0 & -0.408 & -0.272 \\
\hline 011 & $1 \overline{11} 1$ & 0 & 0 & 0.272 \\
\hline 101 & $11 \overline{1}$ & 0.408 & 0.408 & 0.272 \\
\hline 101 & $\overline{111}$ & -0.408 & 0 & 0.272 \\
\hline$\overline{101}$ & $1 \overline{1} 1$ & -0.408 & 0 & 0 \\
\hline$\overline{1} 01$ & $1 \overline{11}$ & -0.408 & 0 & 0 \\
\hline$\overline{1} 10$ & $11 \overline{1}$ & -0.408 & 0 & 0 \\
\hline$\overline{1} 10$ & 111 & -0.408 & 0 & 0 \\
\hline $0 \overline{1} 1$ & $1 \overline{1} \overline{1}$ & 0 & 0 & 0 \\
\hline $0 \overline{1} 1$ & 111 & 0 & -0.408 & 0 \\
\hline $1 \overline{2} 1$ & 111 & 0.236 & -0.236 & 0 \\
\hline$\overline{2} 11$ & 111 & -0.471 & -0.236 & 0 \\
\hline $11 \overline{2}$ & 111 & 0.236 & 0.471 & 0 \\
\hline$\overline{\mathbf{1}} 1 \overline{\mathbf{2}}$ & $\overline{1} 11$ & 0.236 & 0 & -0.157 \\
\hline
\end{tabular}




\begin{tabular}{|c|c|c|c|c|}
\hline 211 & $\overline{1} 11$ & -0.471 & 0 & 0.314 \\
\hline$\overline{12} 1$ & $\overline{1} 11$ & 0.236 & 0 & -0.157 \\
\hline$\overline{1} 21$ & $\overline{111}$ & 0.236 & -0.236 & -0.157 \\
\hline $2 \overline{1} 1$ & $\overline{111}$ & -0.471 & -0.236 & -0.157 \\
\hline$\overline{\mathbf{1 1}} \overline{2}$ & $\overline{111}$ & 0.236 & 0.471 & 0.314 \\
\hline $1 \overline{11} \overline{2}$ & $1 \overline{11} 1$ & 0.236 & 0 & -0.157 \\
\hline$\overline{21} 1$ & $1 \overline{11} 1$ & -0.471 & 0 & -0.157 \\
\hline 121 & $\mathbf{1 1} 1$ & 0.236 & 0 & 0.314 \\
\hline
\end{tabular}

All three orientations have multiple slip systems available, so applying the logic that the orientation with a) the greatest number of slip systems and b) slip systems with the highest value of $M$, one would expect that [100] would be the softest, followed by [110] and finally [111] (more slip systems than [110] but much lower values of $M$ ). However, as we have already shown, the actual ordering is reversed with [100] and [111] being very close and [110] being the softest. In a previous paper ${ }^{31}$, we observed that the ordering of the HEL in aluminium and copper was different, despite them both being face centred cubic and thus likely to obey the Schmid law. The inability to rationalise these results in aluminium and copper was found to be due to the inapplicability of the Schmid factor analysis, which assumes uniaxial stress conditions, to the conditions in a shock. We were able to rationalise those results by using an analysis that is based on a uniaxial strain assumption which incorporates single crystal elasticity using the following equation from Huang and $\mathrm{Asay}^{40}$, derived in turn from the earlier work of Johnson et $a l^{41}$,

$$
H E L_{111}=\frac{\left(C_{11}+2 C_{12}+4 C_{44}\right)\left(C_{11}-C_{12}\right)}{4 C_{11} C_{44}} H E L_{100}
$$


where $C_{11}, C_{12}$ and $C_{44}$ are the elastic constants. Using this approach we were able to correctly order both the aluminium and copper results and, to a reasonable degree reproduce the ratios of the experimental HELs as well. Johnson et $a l^{41}$. demonstrated that the same relations could be used for BCC crystals as well, assuming that slip occurred on the $\{110\}<111>$ systems. We derive the following additional equations from this method as shown below,

$$
\begin{aligned}
& H E L_{111}=\frac{\left(C_{11}+2 C_{12}+4 C_{44}\right)\left(C_{11}-C_{12}+2 C_{44}\right)}{4 C_{44}\left(C_{11}+C_{12}+2 C_{44}\right)} H E L_{110} \text { and } \\
& H E L_{100}=\frac{C_{11}\left(C_{11}-C_{12}+2 C_{44}\right)}{\left(C_{11}-C_{12}\right)\left(C_{11}+C_{12}+2 C_{44}\right)} H E L_{110}
\end{aligned}
$$

Using these relations we determine a theoretical ratio for the HELs in [100] and [110] directions to be 1.15 . This compares to the experimental ratio of 1.47 from this work and 1.41 for the ramped elastic limits (REL) from Asay et $a l^{22}$. We have also made an equivalent comparison of calculated and measured HEL ratios for single crystal molybdenum from the work of Mandal and Gupta ${ }^{42,43}$. We present the results below in Table VI. Whilst the calculated and measured ratios of the HELs in both aluminium and copper are close to their experimentally determined counterparts, and follow the expected ordering, the situation with the BCC tantalum and molybdenum is not so clear cut. The quantitative agreement between ratios is significantly poorer, and in both cases, the ordering between the calculated and measured HEL ratios is not reproduced. This poor correlation in BCC metals is likely to be either due to non-Schmid effects commonly exhibited in BCC metals that are not accounted for in this approach, or significant activity on other slip systems such as $\{112\}<111>$, or twinning.

Table VI. Calculated and measured HEL ratios according to crystal orientation for various FCC and BCC metals. The values in parenthesis are experimentally determined from the cited 
references. The elastic constants for $\mathrm{Al}, \mathrm{Ta}, \mathrm{Cu}$ and Mo are from Thomas ${ }^{44}$, Bolof ${ }^{34}$, Overton and Gafney ${ }^{45}$ and Featherston and Neighbours ${ }^{46}$ respectively.

\begin{tabular}{|c|c|c|c|c|c|c|}
\hline Metal & $C_{11}(\mathrm{GPa})$ & $C_{12}(\mathrm{GPa})$ & $C_{44}(\mathrm{GPa})$ & {$[111] /[100]$} & {$[111] /[110]$} & {$[100] /[110]$} \\
\hline $\mathrm{Al}^{31}$ & 106.8 & 60.4 & 28.3 & $1.31(1.37)$ & $1.39(1.33)$ & $0.94(0.98)$ \\
\hline $\mathrm{Al}^{47}$ & & & & $1.31(1.38)$ & & \\
\hline $\mathrm{Cu}^{48}$ & 168.4 & 121.4 & 75.4 & $0.66(0.69)$ & & \\
\hline $\begin{array}{l}\text { Ta (this } \\
\text { investigation) }\end{array}$ & 267 & 161 & 82.5 & $1.11(0.87)$ & $1.27(1.28)$ & $1.15(1.47)$ \\
\hline $\mathrm{Ta}^{49}$ & & & & & & $1.15(1.41)$ \\
\hline $\mathrm{Mo}^{42,43}$ & 450.0 & 172.9 & 125.0 & $1.59(1.42)$ & $1.08(1.43)$ & $0.96(1.01)$ \\
\hline
\end{tabular}

Repeating the analysis of Johnson et $a l^{41}$. based on the $\{211\}[111]$ system, whilst assuming the Schmid law is still obeyed for these slip systems, generates identical relationships for the HEL ratios as those given above, and therefore identical values as those in Table VI, thus showing that a simple change in slip system cannot explain the observed differences.

The onset of yielding on any slip system $\alpha$ is typically assumed to occur when an effective stress, $\boldsymbol{\tau}_{\boldsymbol{e f f}}^{\alpha}$ reaches a critical material dependent value $\tau_{\text {crit. }}$. For materials that obey the Schmid law, this effective stress is the Schmid stress - the stress resolved in the slip direction, on the slip plane. In order to incorporate non-Schmid effects, a general non-effective stress model has been proposed, first by Qin and Bassani ${ }^{50,51}$, and developed by Groger et al ${ }^{52}$, involving a linear 
combination of four stresses, two of which are parallel, and two perpendicular to the slip direction,

$\hat{\tau}_{e f f}^{\alpha}=\tau_{0}^{\alpha}+a_{1} \tau_{1}^{\alpha}+a_{2} \tau_{2}^{\alpha}+a_{3} \tau_{3}^{\alpha}$

where $\alpha_{1}, \alpha_{2}$ and $\alpha_{3}$ are material parameters, $\boldsymbol{\tau}_{\mathbf{0}}^{\alpha}$ is the Schmid stress, and $\boldsymbol{\tau}_{\mathbf{1}}^{\alpha}$ is a stress component that is also parallel with the slip direction (and therefore contributes to the PeachKoehler force on dislocations) but in a plane that is not parallel with the slip plane. Terms $\boldsymbol{\tau}_{\mathbf{0}}^{\boldsymbol{\alpha}}$ and $\boldsymbol{\tau}_{\mathbf{1}}^{\alpha}$ capture the twinning anti-twinning asymmetry observed in BCC metals. Parameter $a_{1}$ characterises the strength of the twinning anti-twinning asymmetry. The last two terms capture the effect of shear stress perpendicular to the slip directions on the activation of slip systems. All terms are defined in detail in the Appendix. In this work we incorporate twinning/antitwinning asymmetry (T/AT) by retaining the first two terms of this effective stress model. We ignore non-Schmid effects that may result from shear components perpendicular to the slip direction by discarding the second two terms (equivalent to setting $a_{2}=a_{3}=0$ ). This was done in order to simplify the exposition here, as adjusting the $a_{2}$ and $a_{3}$ parameters away from zero did not help us to match our experimental data. We thus derive the following relations for the HEL ratios. Details of how these were derived for the general case of $a_{1}, a_{2}, a_{3} \neq 0$ are given in the Appendix.

$$
\begin{aligned}
& H E L_{111}=\frac{\left(C_{11}+2 C_{12}+4 C_{44}\right)\left(C_{11}-C_{12}\right)}{4 C_{11} C_{44}\left(1+a_{1}\right)} H E L_{100} \\
& H E L_{111}=\frac{\left(C_{11}+2 C_{12}+4 C_{44}\right)\left(C_{11}-C_{12}+2 C_{44}\right)}{4 C_{44}\left(C_{11}+C_{12}+2 C_{44}\right)} H E L_{110} \text { and } \\
& H E L_{100}=\frac{C_{11}\left(C_{11}-C_{12}+2 C_{44}\right)\left(1+a_{1}\right)}{\left(C_{11}-C_{12}\right)\left(C_{11}+C_{12}+2 C_{44}\right)} H E L_{110}
\end{aligned}
$$


Note that the original relations that derive from the model of Johnson et $a l^{41}$. are recovered when $a_{1}=0$. Using this model we are able to obtain an excellent quantitative match to the HEL ratios for tantalum using a value of $a_{1}=0.275$. We also obtain a good match for molybdenum with $a_{1}=0.07$. The results are summarised in Table VII.

Table VII. Summary of experimental and theoretical HEL ratios using equations 6, 7 and 9.

\begin{tabular}{|c|c|c|c|c|}
\hline Material & Data Source & [111]/100] & {$[111] /[110]$} & {$[100] /[110]$} \\
\hline \multirow[t]{2}{*}{$\mathrm{Al}$} & $\operatorname{Expt}^{31}$ & 1.37 & 1.33 & 0.97 \\
\hline & Johnson et $a l^{41}$ & 1.31 & 1.39 & 0.94 \\
\hline \multirow[t]{4}{*}{ Ta } & Expt (this investigation) & 0.87 & 1.28 & 1.47 \\
\hline & Johnson et $a l^{41}$ & 1.11 & 1.27 & 1.15 \\
\hline & TAT Model $\left(a_{1}=0.9\right.$ from MD) & 0.58 & 1.27 & 2.20 \\
\hline & TAT model $\left(a_{1}=0.275\right)$ & 0.87 & 1.27 & 1.47 \\
\hline \multirow[t]{3}{*}{ Mo } & $\operatorname{Expt}^{42,43}$ & 1.42 & 1.43 & 1.01 \\
\hline & Johnson et $a l^{4 l}$ & 1.60 & 1.56 & 0.98 \\
\hline & TAT model $\left(a_{1}=0.07\right)$ & 1.49 & 1.56 & 1.05 \\
\hline
\end{tabular}


There is a high degree of uncertainty in the literature over the parameters $a_{1}, a_{2}$ and $a_{3}$. Estimates have been made for some BCC metals by considering dislocation mobility in atomistic simulations and by fitting to experimental data. Lim et $a l^{53}$. have estimated values based on a number of different experimental studies of quasi-static tension - compression asymmetry and found they can vary considerably. They identified that non-Schmid effects become negligible at quasi-static strain-rates at room temperature, but are significant at $77 \mathrm{~K}$. Some of their estimates are close to the values discussed in this work. For example, they estimated values that are equivalent to $a_{1}=0.17, a_{2}=0.05$ and $a_{3}=-0.01$ based on tensile experiments done at $273 \mathrm{~K}$ and parameters equivalent to $a_{1}=0.35, a_{2}=0.09$ and $a_{3}=0.25$ from tension-compression experiments performed at $77 \mathrm{~K}$. Cho et $a l^{54}$. have estimated values for tantalum of $a_{1}=0.5$, $a_{2}=0.2$ and $a_{3}=0.1$, based on fitting a crystal plasticity model to data from the same experiment at $77 \mathrm{~K}$. They also estimated values for molybdenum of $a_{1}=0.325, a_{2}=0.2$ and $a_{3}=0.65$, based on data from MS simulations at $\mathrm{T}=0 \mathrm{~K}$. Other MS data ${ }^{55}$ indicate values for tantalum of $a_{1} \approx 0.9$ and $a_{1} \approx 0.3$ for molybdenum at $\mathrm{T}=0 \mathrm{~K}$. Predictions of HEL ratios for tantalum from a nonSchmid model with $a_{1}=0.9$ have been included in Table VII for interest. This model does predict the correct ordering of HEL magnitudes, but it does not get the HEL ratios as quantitatively accurate as the model with $a_{1}=0.275$. The parameters $a_{1}, a_{2}, a_{3}$ are expected to vary with temperature, pressure and strain-rate, hence it is not surprising that values estimated here are different to those estimated from low strain-rate, low temperature experiments and modelling, under which the other parameters from the literature were derived.

\section{CONCLUSIONS}

A series of shock loading experiments have been performed on single crystals of tantalum, with the loading axis in the three principal directions of the BCC lattice - [100], [110] 
and [111]. Significant differences have been noticed in the Hugoniot and Hugoniot Elastic Limit according to orientation. The Hugoniot in the [111] and [110] orientations show similar behaviour to polycrystalline material, but the [100] orientation has slightly lower shock speeds. This has been attributed to the lower wave speed in the [100] orientation. We have also noted that at low $\left(<0.1 \mathrm{~mm} \mathrm{~ms}^{-1}\right)$ particle velocities all orientations show a drop below the expected linear behaviour. We believe that this is due to the instabilities at low shock stresses making determination of the shock velocity difficult. Differences in the HEL with orientation were also noted. Using a Schmid factor analysis (SFA), it would be expected that the [111] orientation would be the strongest while the [100] would be the softest. However, it was shown that the strengths of the [100] and [111] orientations were near identical with [110] being softest. Previous work has shown that the SFA is not appropriate for use under shock loading conditions since it assumes uniaxial stress. An analysis based on the Schmid law and a more appropriate uni-axial strain assumption was able to rationalise results from shocked FCC copper and aluminium. However, the same could not rationalise our results for single crystal tantalum, the models based on the Schmid law were not able to account for the ordering of HEL magnitudes. We developed an alternative analysis based on a general non-Schmid effective stress model, that incorporates twinning/anti-twinning asymmetry and other non-Schmid effects. With this model we were not only able to capture the ordering of the HEL's but also reproduce their relative magnitudes to good accuracy. We estimated values for material parameters $\boldsymbol{a}_{1}, \boldsymbol{a}_{2}$ and $\boldsymbol{a}_{3}$ that appear in the non-Schmid effective stress model, and compared them with other estimates from the literature measured under quasi-static conditions at very low temperature. These parameters characterise the size of non-Schmid effects. The estimates suggest that nonSchmid effects in these plate impact experiments are dominated by the twinning/antitwinning asymmetry (over the effect of perpendicular shear components), and that non-Schmid effects are less prominent (though still important) than they are under the quasi-static low temperature 
conditions under which the other estimates were made. Similar conclusions were drawn for molybdenum. These estimates may be useful for constraining models relating to the temperature and strain-rate dependence of non-Schmid effects.

\section{ACKNOWLEDGEMENTS}

We would like to thank Professor Ian Jones, Dr. Yu-Lung Chiu and Dr. Bo Pang of the University of Birmingham for providing the transmission electron micrographs of the single crystals. We are also grateful to Steve Johnson of Imperial College London for operating the gas gun.

The data that supports the findings of this study are available within the article [and its supplementary material].

UK Ministry of Defence $\odot$ Crown Owned Copyright 2020/AWE. Published with permission of the Controller of Her Britannic Majesty's Stationery Office. "This document is of United Kingdom origin and contains proprietary information which is the property of the Secretary of State for Defence. It is furnished in confidence and may not be copied, used or disclosed in whole or in part without prior written consent of Defence Intellectual Property Rights DGDCDIPR-PL - Ministry of Defence, Abbey Wood, Bristol, BS34 8JH, England.” 


\section{APPENDIX}

Shock waves generated by plate impact result in conditions of uniaxial strain. The strain $\left(\widehat{\boldsymbol{E}}^{\prime}\right)$ at the peak of the elastic precursor can thus be written in the sample frame as,

$$
\widehat{\boldsymbol{E}}^{\prime}=\left(\begin{array}{ccc}
\widehat{\epsilon^{\prime}} & 0 & 0 \\
0 & 0 & 0 \\
0 & 0 & 0
\end{array}\right)
$$

Following Johnson et $a l^{56}$, the stress at the elastic wave front $\widehat{\boldsymbol{S}}^{\prime}$ is given by Hooke's law,

$\hat{S}_{r s}^{\prime}=C_{r s t u}^{\prime} \hat{E}_{t u}^{\prime}=a_{r i}^{\prime} a_{s j}^{\prime} a_{t k}^{\prime} a_{u l}^{\prime} C_{i j k l} \hat{E}_{t u}^{\prime}=a_{r i}^{\prime} a_{s j}^{\prime} a_{1 k}^{\prime} a_{1 l}^{\prime} C_{i j k l} \hat{\epsilon}^{\prime}=R_{r s} \hat{\epsilon}^{\prime}$,

where $\mathbf{C}$ is the elastic stiffness tensor in the crystal reference frame and $\boldsymbol{a}^{\prime}$ is the matrix that transforms from the crystal coordinates to the sample coordinates. Values in the crystal reference frame are unprimed. From this equation we can derive a relationship between the full stress tensor at the precursor wave front $\widehat{\boldsymbol{S}}^{\prime}$ and the precursor magnitude $\hat{\sigma}^{\prime}\left(=\hat{S}_{11}^{\prime}\right)$. Matrices $a^{\prime}$ and $\widehat{\boldsymbol{S}}^{\prime} / \hat{\sigma}^{\prime}$ are given below for the three wave propagation directions under consideration here, [100], [110] and [111].

For [100] propagation,

$\boldsymbol{a}^{\prime}=\boldsymbol{I} \quad$ and

$\frac{\widehat{\boldsymbol{s}}^{\prime}}{\widehat{\sigma}^{\prime}}=\frac{1}{C_{11}}\left(\begin{array}{ccc}C_{11} & 0 & 0 \\ 0 & C_{12} & 0 \\ 0 & 0 & C_{12}\end{array}\right)$.

For [110] wave propagation,

$$
\boldsymbol{a}^{\prime}=\left(\begin{array}{ccc}
\frac{1}{\sqrt{2}} & \frac{1}{\sqrt{2}} & 0 \\
-\frac{1}{\sqrt{2}} & \frac{1}{\sqrt{2}} & 0 \\
0 & 0 & 1
\end{array}\right) \text { and }
$$




$$
\begin{aligned}
& \frac{\widehat{\widehat{S}}^{\prime}}{\widehat{\widehat{\sigma}}^{\prime}}=\frac{1}{\frac{1}{2}\left(C_{11}+C_{12}+2 C_{44}\right)} \times \\
& \left(\begin{array}{ccc}
\frac{1}{2}\left(C_{11}+C_{12}+2 C_{44}\right) & 0 & 0 \\
0 & \frac{1}{2}\left(C_{11}+C_{12}-2 C_{44}\right) & 0 \\
0 & 0 & C_{12}
\end{array}\right) .
\end{aligned}
$$

For [111] propagation,

$$
\begin{aligned}
& \boldsymbol{a}^{\prime}=\left(\begin{array}{ccc}
\frac{1}{\sqrt{3}} & \frac{1}{\sqrt{3}} & \frac{1}{\sqrt{3}} \\
\frac{1}{\sqrt{2}} & -\frac{1}{\sqrt{2}} & 0 \\
\frac{1}{\sqrt{6}} & \frac{1}{\sqrt{6}} & -\frac{2}{\sqrt{3}}
\end{array}\right) \text { and } \\
& \frac{\widehat{\widehat{s}}^{\prime}}{\widehat{\sigma}^{\prime}}=\frac{1}{\frac{1}{3}\left(C_{11}+2 C_{12}+4 C_{44}\right)} \times \\
& \left(\begin{array}{ccc}
\frac{1}{3}\left(C_{11}+2 C_{12}+4 C_{44}\right) & 0 \\
0 & \frac{1}{3}\left(C_{11}+2 C_{12}-2 C_{44}\right) & 0 \\
0 & 0 & \frac{1}{3}\left(C_{11}+2 C_{12}-2 C_{44}\right)
\end{array}\right) .
\end{aligned}
$$

Finally, we obtain relationships between the elastic precursor magnitude $\widehat{\boldsymbol{\sigma}}^{\prime}$ (note that this term appears as HEL in the main body of the text) and the effective stress $\hat{\tau}_{\text {eff }}$ by calculating from $\widehat{\boldsymbol{S}}^{\prime}$. For a single crystal material that conforms with the Schmid law (such as FCC metals) the effective stress may be defined for each slip system $\alpha$ as the Schmid stress, i.e. the stress resolved parallel to the slip direction unit vector $\mathbf{m}^{\alpha}$ and the plane defined by slip plane normal unit vector $\mathbf{n}^{\alpha}$ given by,

$\hat{\tau}_{e f f}^{\alpha}=\boldsymbol{m}^{\alpha} \widehat{\boldsymbol{S}} \boldsymbol{n}^{\alpha}=m_{m}^{\alpha} n_{n}^{\alpha} a_{i m}^{\prime} a_{j n}^{\prime} \hat{S}_{i j}^{\prime}$ 
Initial yielding is assumed to be controlled by the slip system with the largest (effective) Schmid stress. In the analysis of Johnson et $\mathrm{l}^{41}$, slip systems were assumed to of type $\{01 \overline{1}\}\langle 111\rangle$ (i.e. $\boldsymbol{m}^{\alpha}=\langle 111\rangle$ and $\left.\boldsymbol{n}^{\alpha}=\{01 \overline{1}\}\right)$, of which there are twelve. To incorporate non-Schmid effects, following the approach of Groger $e t a l^{9}$, a general effective stress is used instead,

$\hat{\tau}_{e f f}^{\alpha}=\tau_{0}^{\alpha}+a_{1} \tau_{1}^{\alpha}+a_{2} \tau_{2}^{\alpha}+a_{3} \tau_{3}^{\alpha}$

Where $\tau_{0}^{\alpha}=\boldsymbol{m}^{\alpha} \widehat{\boldsymbol{S}} \boldsymbol{n}^{\alpha}$ is the Schmid stress, $\tau_{1}^{\alpha}=\boldsymbol{m}^{\alpha} \widehat{\boldsymbol{S}} \boldsymbol{n}_{1}^{\alpha}$ is a stress parallel to the slip direction but in a plane defined by unit vector $\boldsymbol{n}_{1}^{\alpha}$ that is in the same plane as $\boldsymbol{n}^{\alpha}$. Terms $\tau_{0}^{\alpha}$ and , $\tau_{1}^{\alpha}$ capture the twinning-anti-twinning asymmetry observed in BCC metals. The last two terms $\tau_{2}^{\alpha}=\left(\boldsymbol{n}^{\alpha} \times \boldsymbol{m}^{\alpha}\right) \widehat{\boldsymbol{S}} \boldsymbol{n}^{\alpha}$ and $\tau_{3}^{\alpha}=\left(\boldsymbol{n}_{1}^{\alpha} \times \boldsymbol{m}^{\alpha}\right) \widehat{\boldsymbol{S}} \boldsymbol{n}_{1}^{\alpha}$ capture the effect of shear stress perpendicular to the slip directions on the activation of slip systems. The 24 BCC slip systems based on the $\{110\}$ planes are listed below in Table VIII.

Table VIII. The $24\{110\}$ based slip systems in BCC crystals. Note that the crystallographic vectors $\mathbf{m}^{\alpha}, \mathbf{n}^{\alpha}$ and $\boldsymbol{n}_{1}^{\alpha}$ have been normalised before use in the equations.

\begin{tabular}{|l|l|l|l|l||l|l|l|l|c|}
\hline$\alpha$ & $\begin{array}{l}\text { Reference } \\
\text { System }\end{array}$ & $\mathbf{m}^{\alpha}$ & $\mathbf{n}^{\alpha}$ & $\boldsymbol{n}_{1}^{\alpha}$ & $\alpha$ & Reference & $\mathbf{m}^{\alpha}$ & $\mathbf{n}^{\alpha}$ & $\boldsymbol{n}_{1}^{\alpha}$ \\
\hline 1 & $(01 \overline{1})[111]$ & {$[111]$} & {$[01 \overline{1}]$} & {$[\overline{1} 10]$} & 13 & $(01 \overline{1})[\overline{1} \overline{1} \overline{1}]$ & {$[\overline{1} \overline{1} \overline{1}]$} & {$[01 \overline{1}]$} & {$[10 \overline{1}]$} \\
\hline 2 & $(\overline{1} 01)[111]$ & {$[111]$} & {$[\overline{1} 01]$} & {$[0 \overline{1} 1]$} & 14 & $(\overline{1} 01)[\overline{1} \overline{1} \overline{1}]$ & {$[\overline{1} \overline{1} \overline{1}]$} & {$[\overline{1} 01]$} & {$[\overline{1} 10]$} \\
\hline 3 & $(1 \overline{1} 0)[111]$ & {$[111]$} & {$[1 \overline{1} 0]$} & {$[10 \overline{1}]$} & 15 & $(1 \overline{1} 0)[\overline{1} \overline{1} \overline{1}]$ & {$[\overline{1} \overline{1} \overline{1}]$} & {$[1 \overline{1} 0]$} & {$[0 \overline{1} 1]$} \\
\hline 4 & $(\overline{1} 0 \overline{1})[\overline{1} 11]$ & {$[\overline{1} 11]$} & {$[\overline{1} 0 \overline{1}]$} & {$[\overline{1} \overline{1} 0]$} & 16 & $(\overline{1} 0 \overline{1})[1 \overline{1} \overline{1}]$ & {$[1 \overline{1} \overline{1}]$} & {$[\overline{1} 0 \overline{1}]$} & {$[01 \overline{1}]$} \\
\hline
\end{tabular}




\begin{tabular}{|l|l|l|l|l||l|l|l|l|l|}
\hline 5 & $(0 \overline{1} 1)[\overline{1} 11]$ & {$[\overline{1} 11]$} & {$[0 \overline{1} 1]$} & {$[101]$} & 17 & $(0 \overline{1} 1)[1 \overline{1} \overline{1}]$ & {$[1 \overline{1} \overline{1}]$} & {$[0 \overline{1} 1]$} & {$[\overline{1} \overline{1} 0]$} \\
\hline 6 & $(110)[\overline{1} 11]$ & {$[\overline{1} 11]$} & {$[110]$} & {$[01 \overline{1}]$} & 18 & $(110)[1 \overline{1} \overline{1}]$ & {$[1 \overline{1} \overline{1}]$} & {$[110]$} & {$[101]$} \\
\hline 7 & $(0 \overline{1} \overline{1})[\overline{1} \overline{1} 1]$ & {$[\overline{1} \overline{1} 1]$} & {$[0 \overline{1} \overline{1}]$} & {$[1 \overline{1} 0]$} & 19 & $(0 \overline{1} \overline{1})[11 \overline{1}]$ & {$[11 \overline{1}]$} & {$[0 \overline{1} \overline{1}]$} & {$[\overline{1} 0 \overline{1}]$} \\
\hline 8 & $(101)[\overline{1} \overline{1} 1]$ & {$[\overline{1} \overline{1} 1]$} & {$[101]$} & {$[011]$} & 20 & $(101)[11 \overline{1}]$ & {$[11 \overline{1}]$} & {$[101]$} & {$[1 \overline{1} 0]$} \\
\hline 9 & $(\overline{1} 10)[\overline{1} \overline{1} 1]$ & {$[\overline{1} \overline{1} 1]$} & {$[\overline{1} 10]$} & {$[\overline{1} 0 \overline{1}]$} & 21 & $(\overline{1} 10)[11 \overline{1}]$ & {$[11 \overline{1}]$} & {$[\overline{1} 10]$} & {$[011]$} \\
\hline 10 & $(10 \overline{1})[1 \overline{1} 1]$ & {$[1 \overline{1} 1]$} & {$[10 \overline{1}]$} & {$[110]$} & 22 & $(10 \overline{1})[\overline{1} 1 \overline{1}]$ & {$[\overline{1} 1 \overline{1}]$} & {$[10 \overline{1}]$} & {$[0 \overline{1} \overline{1}]$} \\
\hline 11 & $(011)[1 \overline{1} 1]$ & {$[1 \overline{1} 1]$} & {$[011]$} & {$[\overline{1} 01]$} & 23 & $(011)[\overline{1} 1 \overline{1}]$ & {$[\overline{1} 1 \overline{1}]$} & {$[011]$} & {$[110]$} \\
\hline 12 & $(\overline{1} \overline{1} 0)[1 \overline{1} 1]$ & {$[1 \overline{1} 1]$} & {$[\overline{1} \overline{1} 0]$} & {$[0 \overline{1} \overline{1}]$} & 24 & $(\overline{1} \overline{1} 0)[\overline{1} 1 \overline{1}]$ & {$[\overline{1} 1 \overline{1}]$} & {$[\overline{1} \overline{1} 0]$} & {$[\overline{1} 01]$} \\
\hline
\end{tabular}

As noted by Groger et $a l^{9}$, only reference systems with positive Schmid stresses and positive stresses on the $\mathbf{n}_{1}$ planes are considered by construction. Therefore, working through the algebra yields the following relations:

For [100] wave propagation,

$\frac{\hat{\tau}}{\widehat{\sigma}^{\prime}}=\frac{1}{\sqrt{6} C_{11}}\left(C_{11}-C_{12}\right)\left(1-\frac{a_{2}}{\sqrt{2}}\right)$, A8

for [110] wave propagation

$\frac{\hat{\tau}}{\widehat{\sigma}^{\prime}}=\frac{1}{\sqrt{6}\left(C_{11}+C_{12}+2 C_{44}\right)} \times$

$\left[\left(C_{11}-C_{12}+2 C_{44}\right)\left(1+a_{1}\right)+\frac{1}{\sqrt{2}}\left(C_{11}-C_{12}-4 C_{44}\right)\left(a_{3}-a_{2}\right)\right]$

and for [111] propagation, 


$$
\frac{\hat{\tau}}{\hat{\sigma}^{\prime}}=\frac{4 C_{44}}{\sqrt{6}\left(C_{11}+2 C_{12}+4 C_{44}\right)}\left(1+a_{1}+\sqrt{2}\left(a_{2}-a_{3}\right)\right) .
$$

Dividing one of the three previous relations by one of the other yields the following HEL ratios, thus,

$$
\begin{aligned}
& \frac{\widehat{\sigma}_{[111]}^{\prime}}{\widehat{\sigma}_{[100]}^{\prime}}=\frac{\left(C_{11}+2 C_{12}+4 C_{44}\right)\left(C_{11}-C_{12}\right)}{4 C_{11} C_{44}}\left(\frac{1-\frac{a_{2}}{\sqrt{2}}}{1+a_{1}+\sqrt{2}\left(a_{2}-a_{3}\right)}\right), \\
& \frac{\widehat{\sigma}_{[111]}^{\prime}}{\widehat{\sigma}_{[110]}^{\prime}}=\frac{\left(C_{11}+2 C_{12}+4 C_{44}\right)}{4 C_{44}\left(C_{11}+C_{12}+2 C_{44}\right)} \times \\
& \left(\frac{\left(C_{11}-C_{12}+2 C_{44}\right)\left(1+a_{1}\right)+\frac{1}{\sqrt{2}}\left(C_{11}-C_{12}-4 C_{44}\right)\left(a_{3}-a_{2}\right)}{1+a_{1}+\sqrt{2}\left(a_{2}-a_{3}\right)}\right) \\
& \frac{\widehat{\sigma}_{[100]}^{\prime}}{\widehat{\sigma}_{[110]}^{\prime}}=\frac{C_{11}}{\left(C_{11}-C_{12}\right)\left(C_{11}+C_{12}+2 C_{44}\right)} \times \\
& \left(\frac{\left(C_{11}-C_{12}+2 C_{44}\right)\left(1+a_{1}\right)+\frac{1}{\sqrt{2}}\left(C_{11}-C_{12}-4 C_{44}\right)\left(a_{3}-a_{2}\right)}{1-\frac{a_{2}}{\sqrt{2}}}\right) .
\end{aligned}
$$

Setting $a_{2}=a_{3}=0$ yields the equations used in the body of this report. 


\section{REFERENCES}

S. R. Chen and G.T. Gray III, Met. Mat. Trans. A 27A, 2994 (1996).

A. Lawley and H.L. Gaigher, Phil. Mag. 10, 15 (1964).

J. F. Byron, Journal of the Less-Common Metals 14, 201 (1968).

J. F. Byron and D. Hull, Journal of the Less-Common Metals 13, 71 (1967).

C.R. Weinberger, B.L. Boyce, and C.C. Battaile, Int. Mat. Rev. 58:5, 296 (2013).

J.T. Lloyd, J.D. Clayton, R. Becker et al., Int. J. Plasticity 60, 118 (2014).

R.E. Smallman, Modern Physical Metallurgy. (Butterworths, London, 1985).

J.W. Christian, Met. Trans. A 14A, 1237 (1983).

R. Groger, V. Racherla, J.L. Bassani et al., Acta Mater. 56, 5412 (2008).

C.S. Barrett, G. Ansel, and R.F. Mehl, Trans. Am. Soc. Metall. 25, 702 (1937).

D. Caillard, Acta Mater. 58, 3493 (2010).

W.A. Spitzig and T.E. Mitchell, Acta Metall. 14, 1311 (1966).

N.K. Chen and R. Maddin, Acta Metall. 2, 49 (1954).

B. Sestak and A. Seeger, Z. Metallkunde 69, 195 (1978).

B. Sestak and A. Seeger, Z. Metallkunde 69, 355 (1978).

J. Chaussidon, M. Fivel, and D. Rodney, Acta Mater. 54, 3407 (2006).

D. Rittel, M.L. Silva, B. Poon et al., Mech. Mat. 41, 1323 (2009).

R. Kapoor and S. Nemat-Nasser, Scripta Mater. 40 (2), 159 (1999).

A. J. Schwartz, W. E. King, G. H. Campbell et al., J. Eng. Mat. Technol. 121, 178 (1999).

H. Lim, J.D. Carroll, J.R. Michael et al., Acta Mater. 185, 1 (2020).

H. Lim, J.D. Carroll, C.C. Battaile et al., Scientific Reports 8, 1 (2018).

J. R. Asay, T. J. Vogler, T. Ao et al., Journal of Applied Physics 109, 073507 (2011).

J. L. Ding and J. R. Asay, Journal of Applied Physics 109, 083505 (2011).

G. Whiteman, S. Case, and J.C.F. Millett, Journal of Physics: Conference Series 500, 112067 (2014).

J.N. Florando, N. R. Barton, B.S. El-Dasher et al., J. App. Phys 113, 083522 (2013).

L. M. Hsuing and D. H. Lassila, Acta Materialia 48, 4851 (2000).

C.H. Lu, B.A. Remington, B.R. Maddox et al., Acta Mater. 60, 6601 (2012).

J.C.F Millett, G Whiteman, N.T. Park et al., J. App. Phys 113, 233502 (2013).

J.C.F. Millett, G. Whiteman, N.K. Bourne et al., JPhys: Conf. Series 500, 112046 (2014).

B. Pang, I.P. Jones, J.C.F. Millett et al., Acta Mater. 148, 482 (2018).

G. D. Owen, D. J. Chapman, G. Whiteman et al., J. Appl. Phys. 122, 155102 (2017).

J.C.F. Millett, G.T. Gray III, G. Whiteman et al., presented at the DYMAT,

Archachon, France, 2018 (unpublished).

O. T. Strand, Rev. Sci. Instrum. 77, 083018 (2006).

D.I. Bolef, J. Appl. Phys. 32, 100 (1961).

G.T. Gray and C.E. Morris, in Sixth World Conference on Titanium ((unpublished), France, 1988), pp. 269.

S. P. Marsh, LASL Shock Hugoniot Data. (University of California Press, 1980). M.D. Furnish, L.C. Chhabildas, and D.J. Steinberg, presented at the High-Pressure Science and Technology, Colorado Springs, USA, 1993 (unpublished). J.C.F. Millett, M. Cotton, N.K. Bourne et al., J. Appl. Phys. 115, 073506 (2014). P. S. Fiske, N. Holmes, and D. Lassila, presented at the Plasticity 1999, Cancun, Mexico, 1999 (unpublished). 
H. Huang and J.R. Asay, J. Appl. Phys. 100, 043514 (2006).

J.N. Johnson, O.E. Jones, and T.E. Michaels, J. App. Phys 41, 2330 (1970).

A. Mandal and Y.M. Gupta, Journal of Applied Physics 121, 045903 (2017).

A. Mandal and Y.M. Gupta, J. Appl. Phys. 125, 055903 (2019).

J.F. Thomas, Phys. Rev. 175, 955 (1968).

W.C. Overton and J. Gaffney, Phil. Mag. 98, 969 (1955).

F.H. Featherston and J.R. Neighbours, Phys. Rev. 130, 1324 (1963).

H. Huang and J.R. Asay, J. Appl. Phys. 100, 043514 (2006).

D.E. Jones and J.D. Mote, J. Appl. Phys. 40, 4920 (1969).

J.R. Asay, T.J. Vogler, T. Ao et al., J. Appl. Phys. 109, 073507 (2011).

Q. Qin and J.L. Bassani, J. Mech. Phys. Solid 40, 813 (1992).

Q. Qin and J.L. Bassani, J. Mech. Phys. Solid 40, 835 (1992).

R. Groger, A.G. Bailey, and V. Vitek, Acta Mat. 56 (19), 5401 (2008).

H. Lim, C.R. Weinberger, C.C. Battaile et al., Modelling Simul. Mater. Sci. Eng. 21, 045015 (2013).

H. Cho, C.A. Bronkhorst, H.M. Mourad et al., Inter. J. Solids. Structures. 139, 138 (2018).

55

J.A. Moriarty, L.X. Benedict, J.N. Glosli et al., " Robust quantum-based interatomic potentials for multiscale modelling in transition metals" Report No. UCRL-JRNL215739, Lawrence Livermore National Laboratory, Livermore, CA. (2015). J.N. Johnson, O.E. Jones, and T.E. Michaels, J. Appl. Phys. 41, 2330 (1970). 


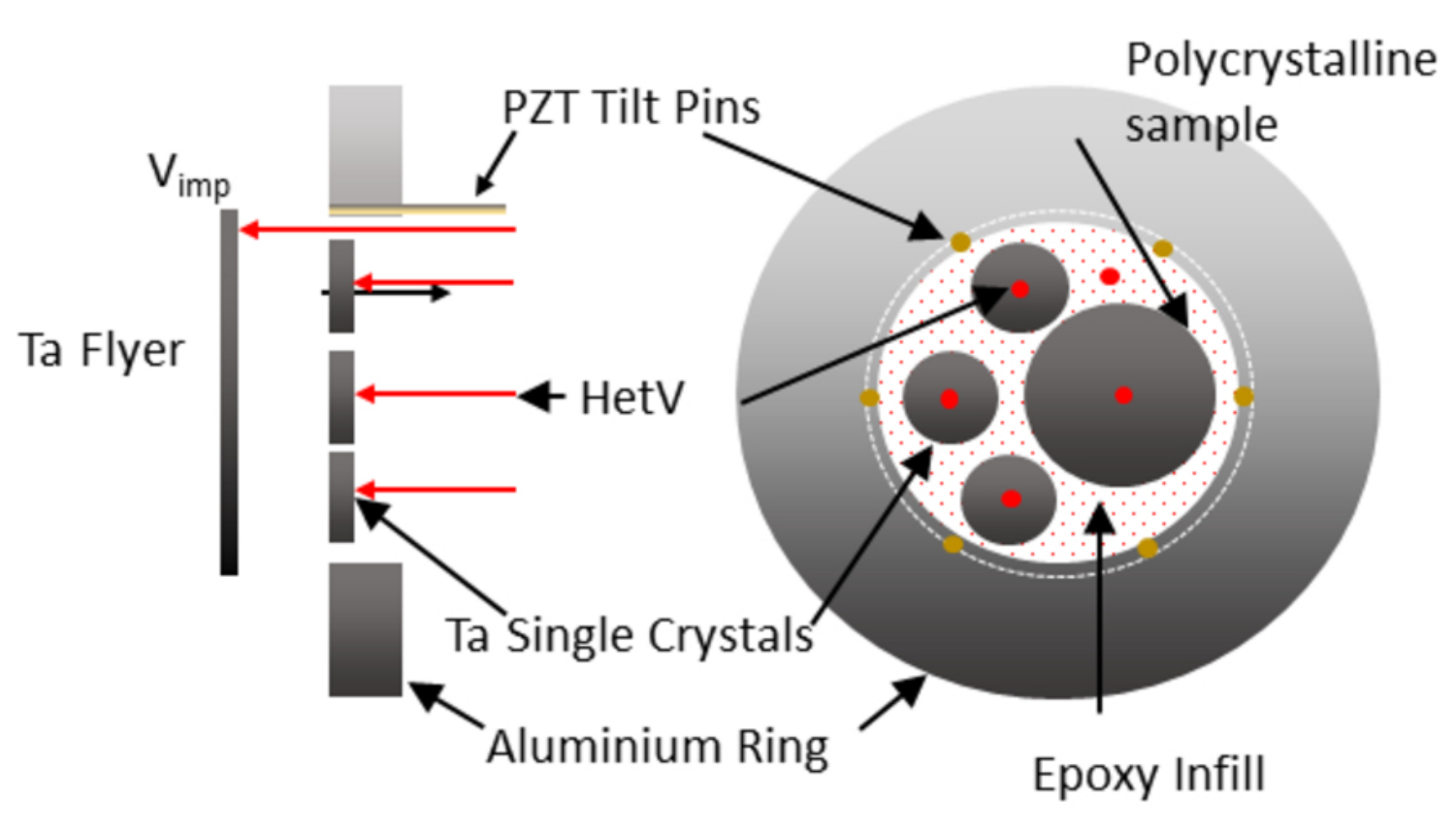

a)

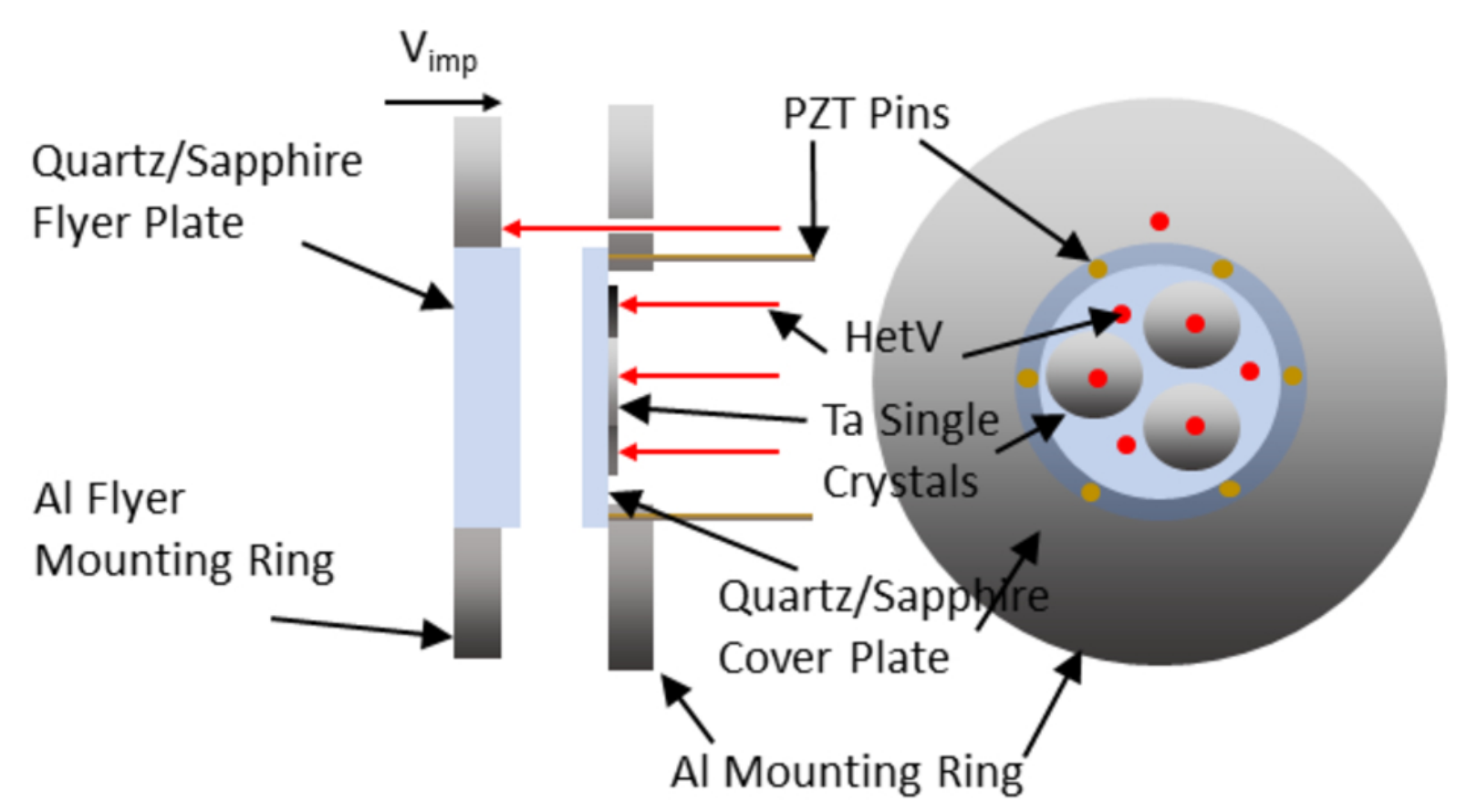

b)

Figure 1: Schematic of target and diagnostic set ups for a) Type 1 geometry and b) Type 2 geometry. 


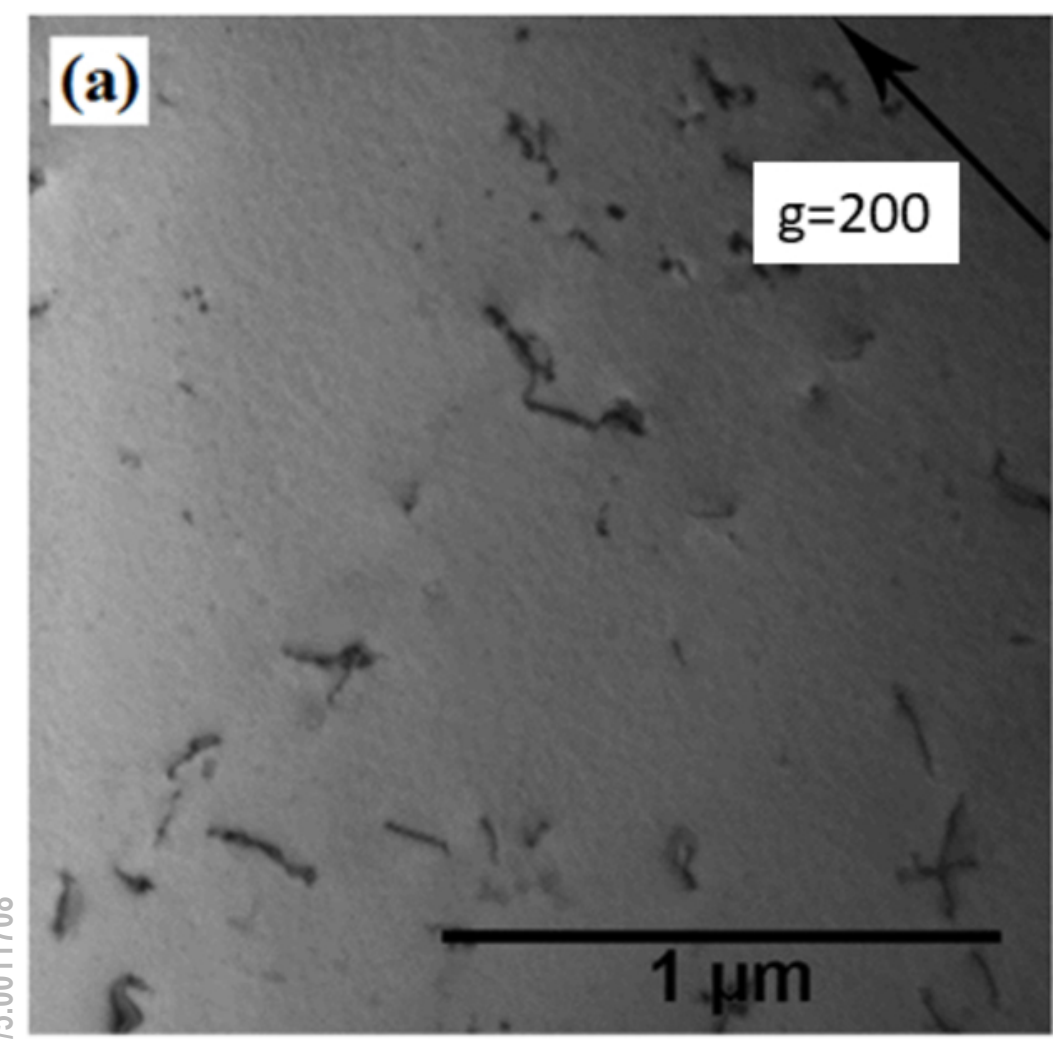

\section{(b)}

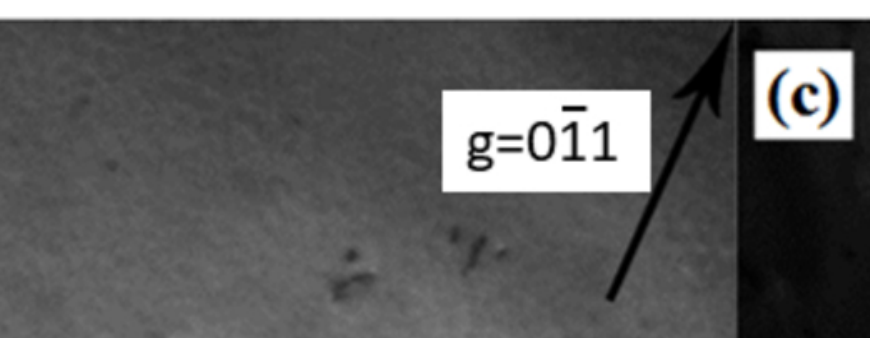

(c)

Figure 2. TEM images of the initial single crystal tantalum sample; a) [100], b [110] and c) [111]. $g$ is the reciprocal lattice vector of the lattice plane giving rise to reflection. 


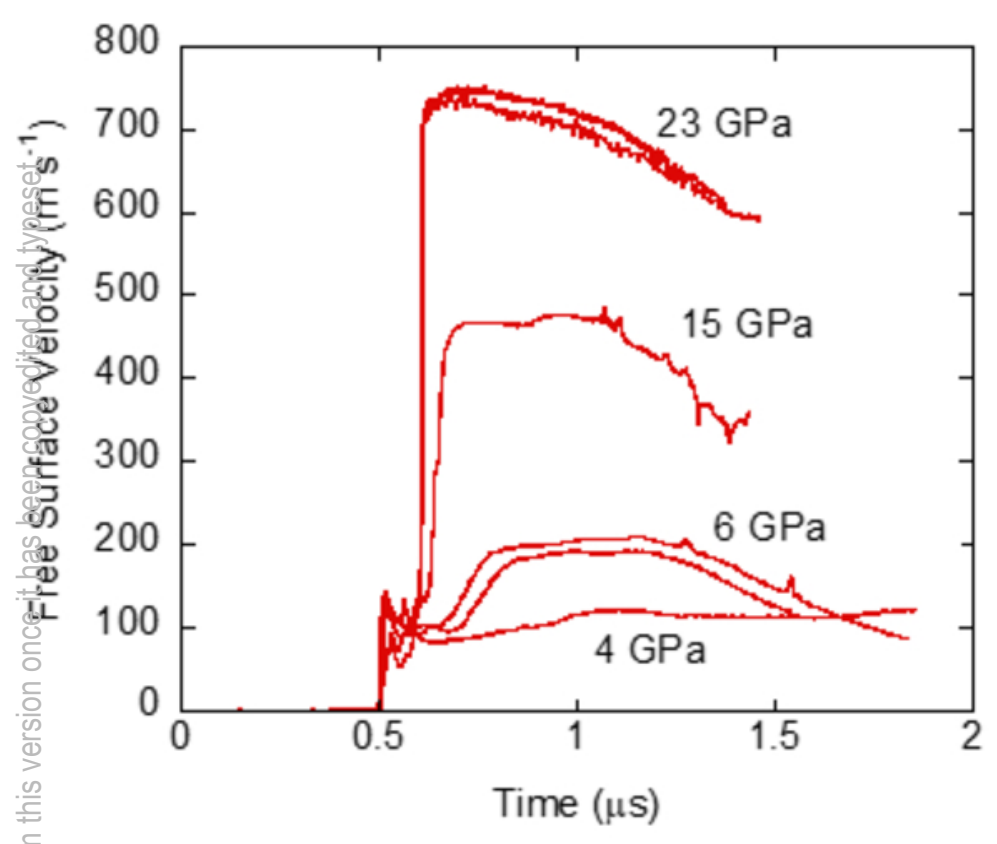

a) [100] orientation

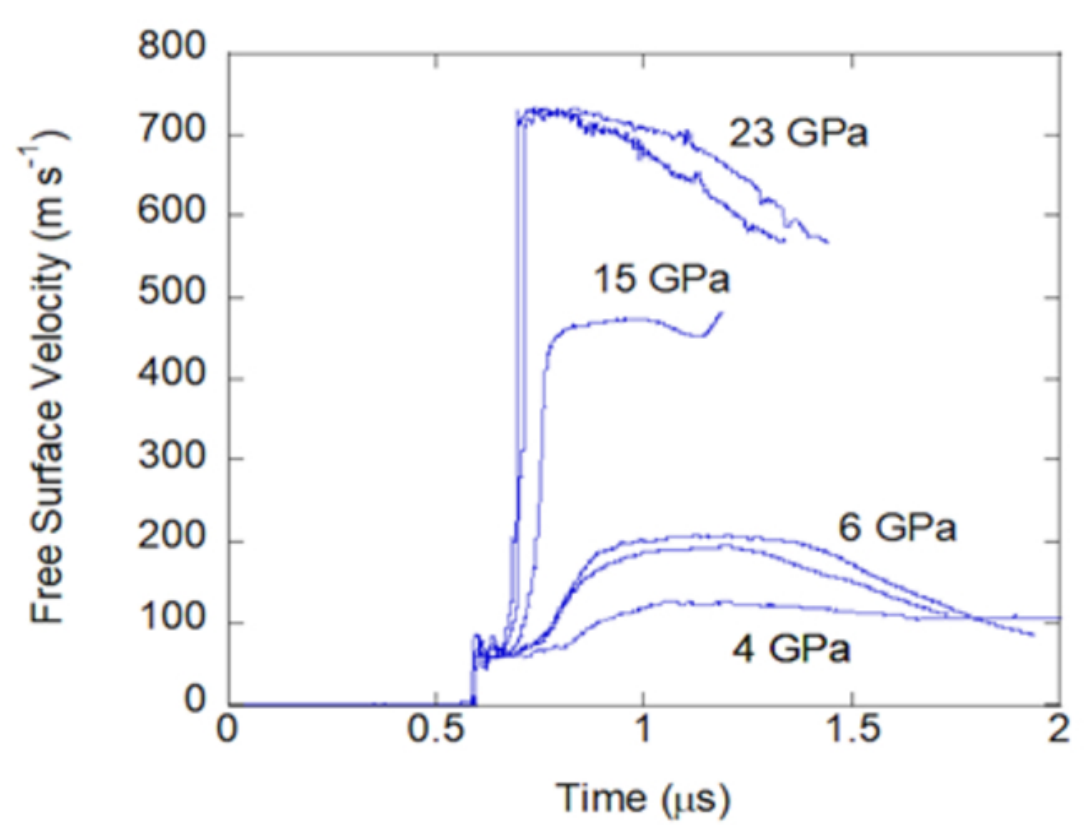

b) [110] orientation

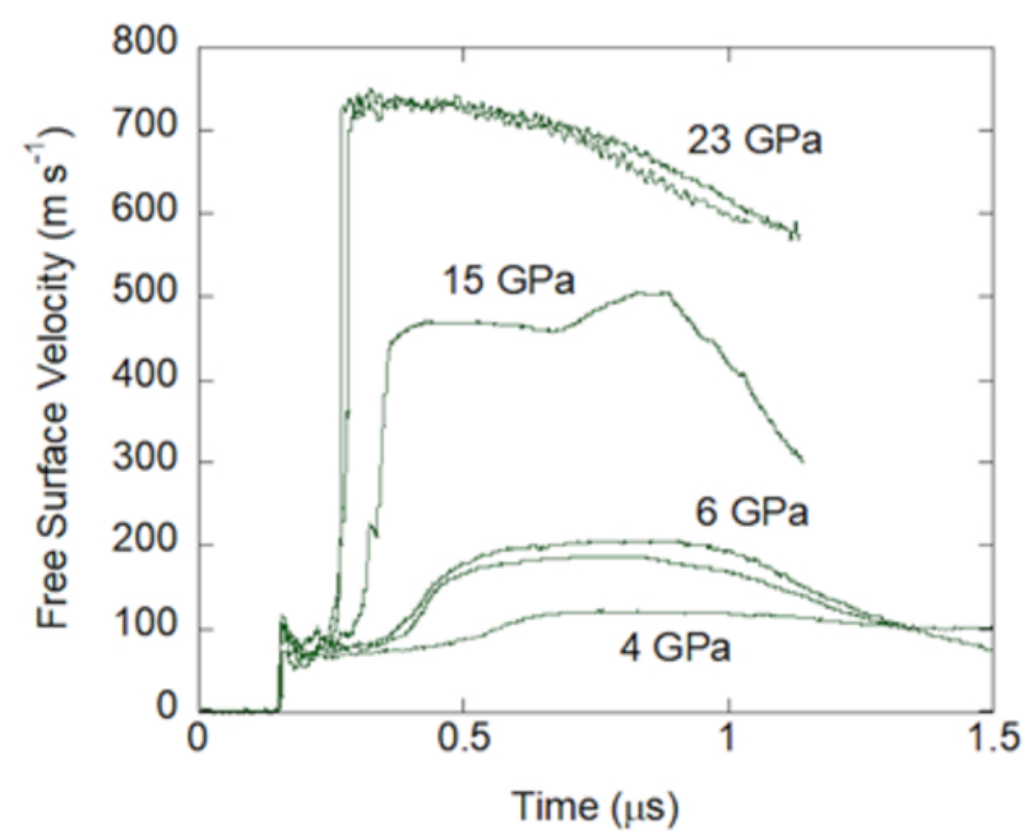

c) [111] orientation

Figure 3. Free surface measurements from $4 \mathrm{~mm}$ crystals, impacted from 4 to 23 GPa. a) [100] orientation, b) [110] orientation and c) [111] orientation. Note that the traces at 6 and $23 \mathrm{GPa}$ have been repeated (shots CSC1-1 and 2, and CSC1-3 and 4 respectively - see Table I). 


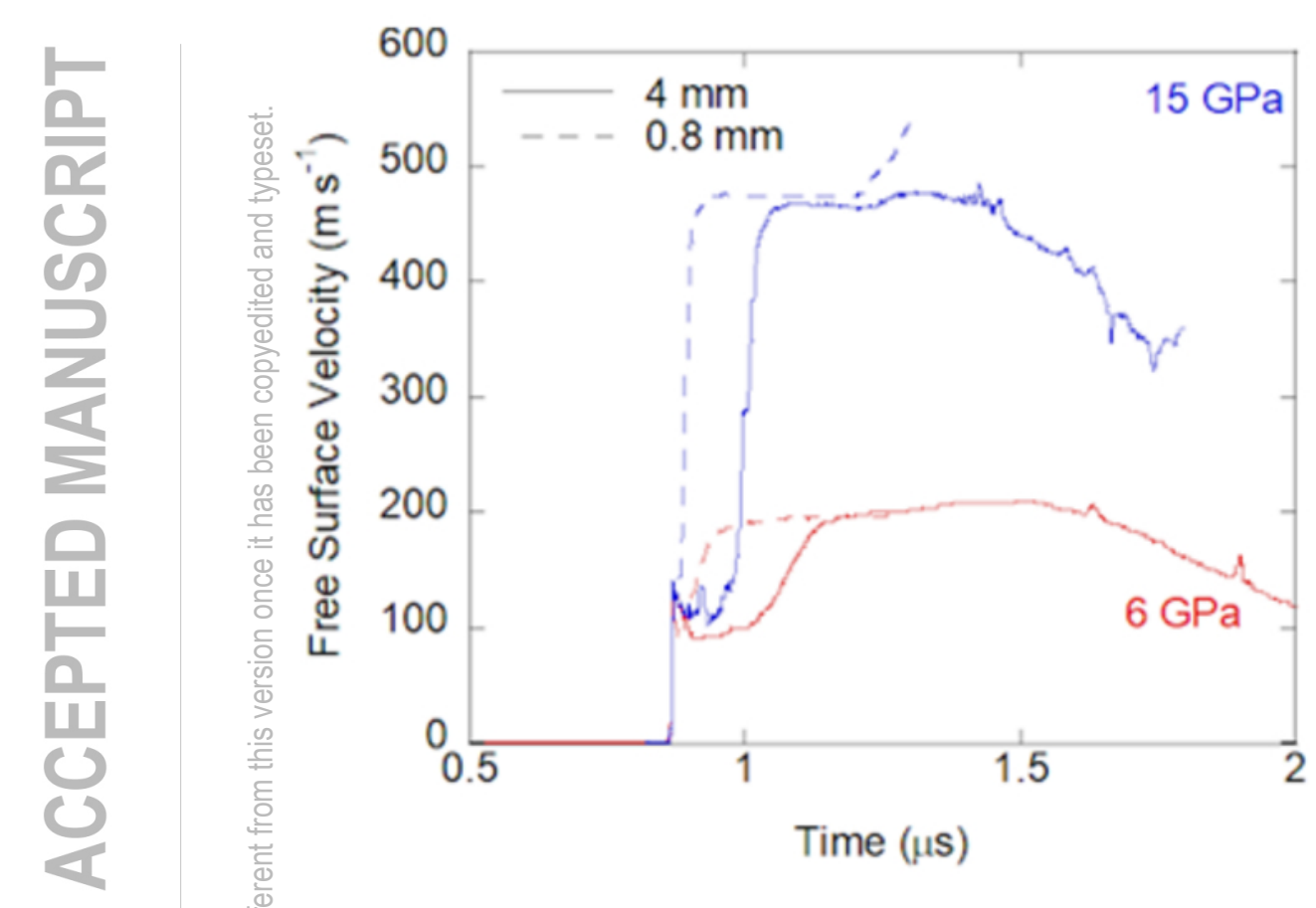

a) [100] orientation

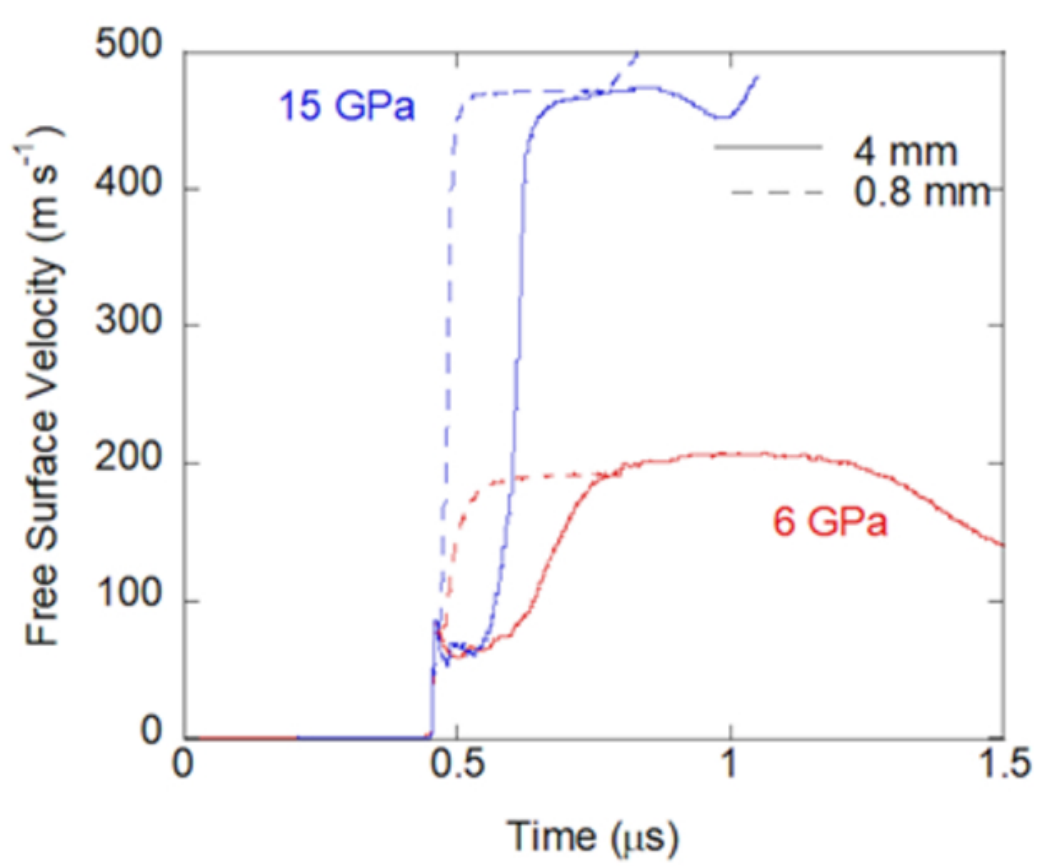

b) [110] orientation

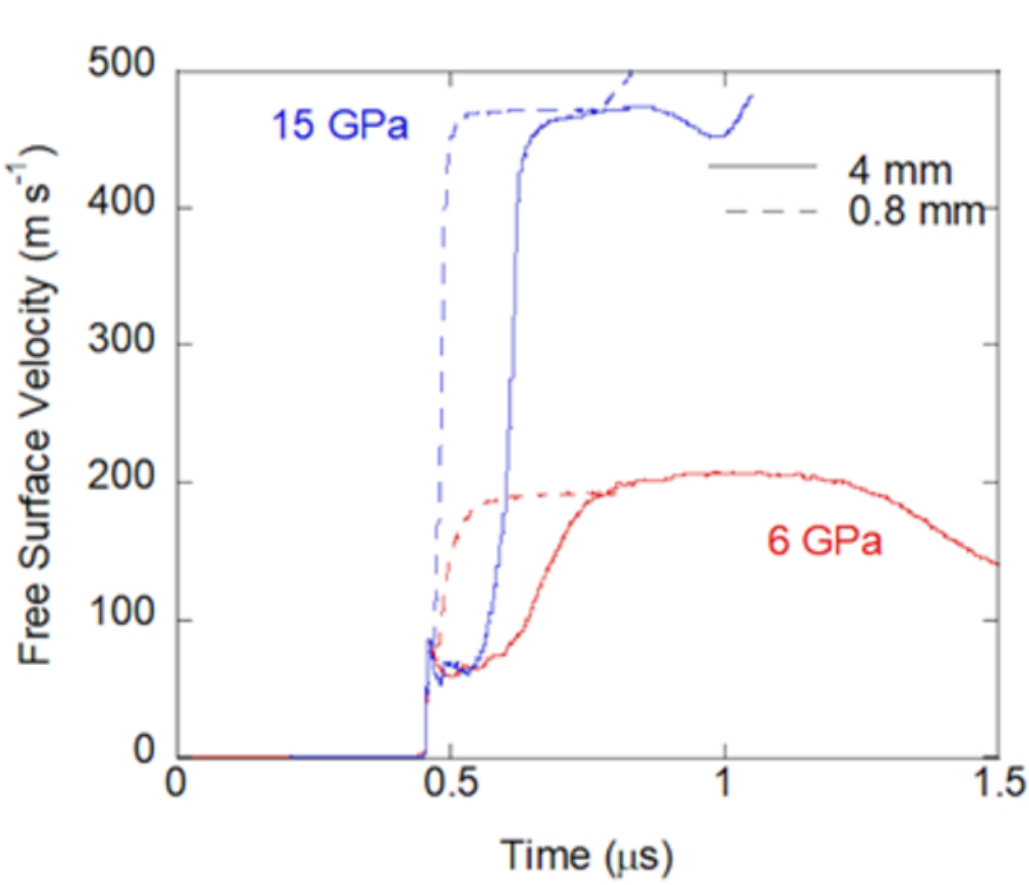

c) [111] orientation

Figure 4. Free surface velocities of single crystal tantalum for crystal thicknesses of 0.8 and $4 \mathrm{~mm}$. a) [100] orientation, b) [110] orientation and c) [111] orientation. 


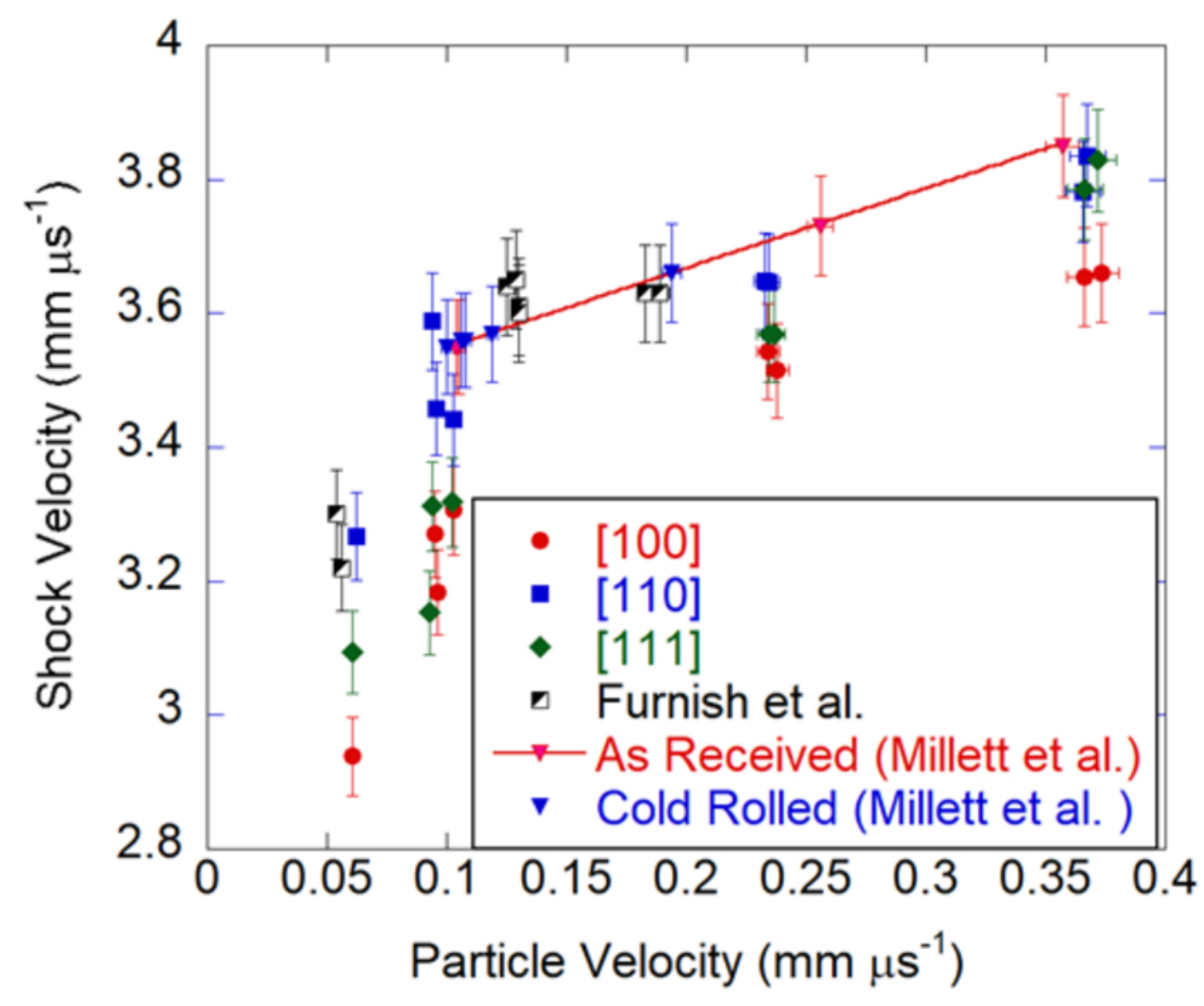

a) shock velocity versus particle velocity

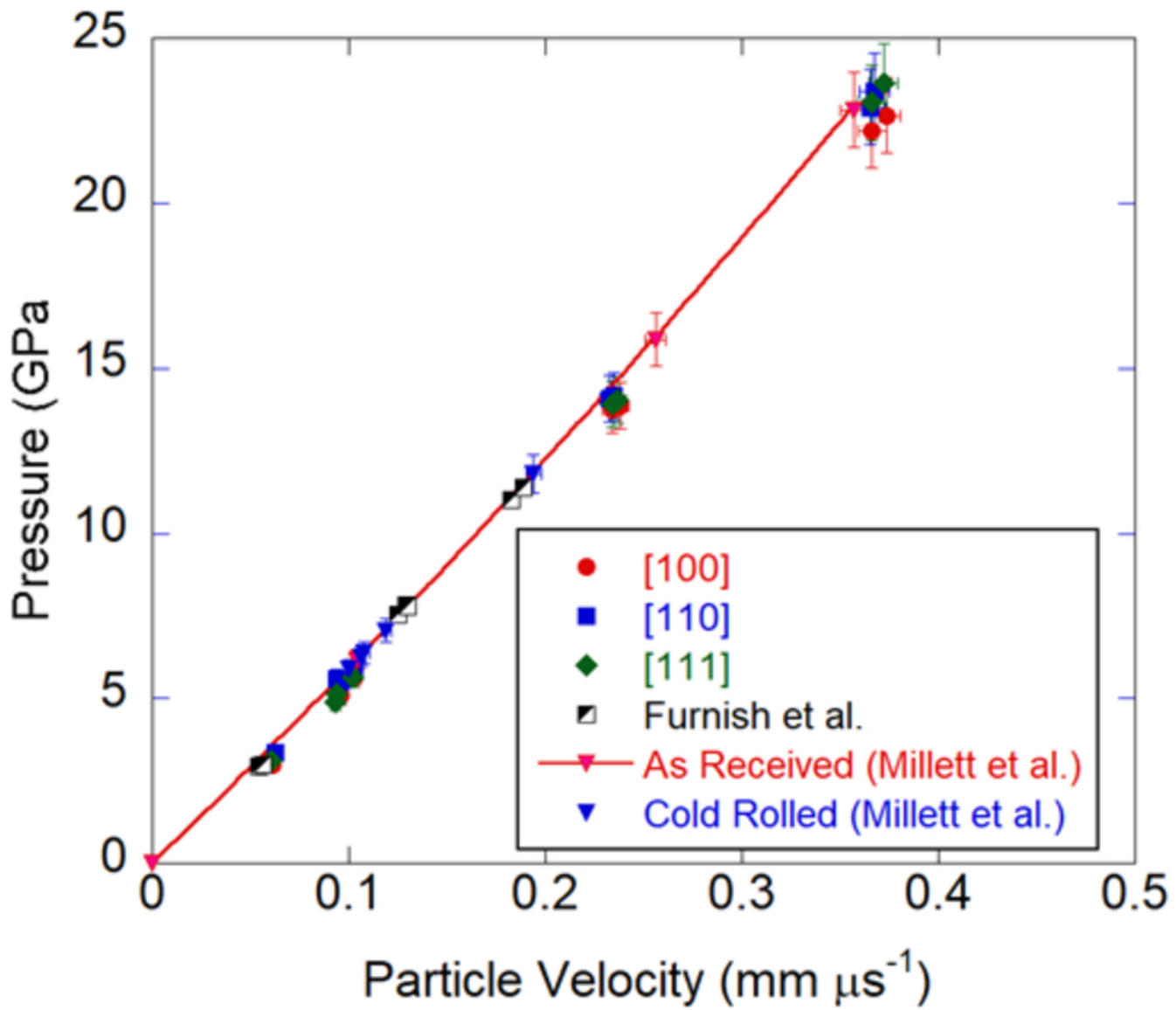

b) pressure versus particle velocity

Figure 5. The shock Hugoniot of tantalum as a function of crystal orientation to the loading axis. a) shock velocity Wersus particle velocity and b) pressure versus particle velocity. Data from the polycrystalline work of both Furnish et

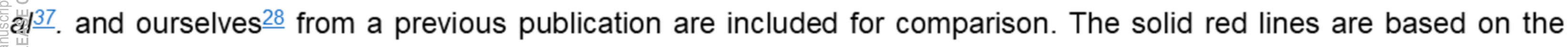
relation from Marsh $\frac{36}{2}-U_{S}=3.43+1.19 u_{p}$. 


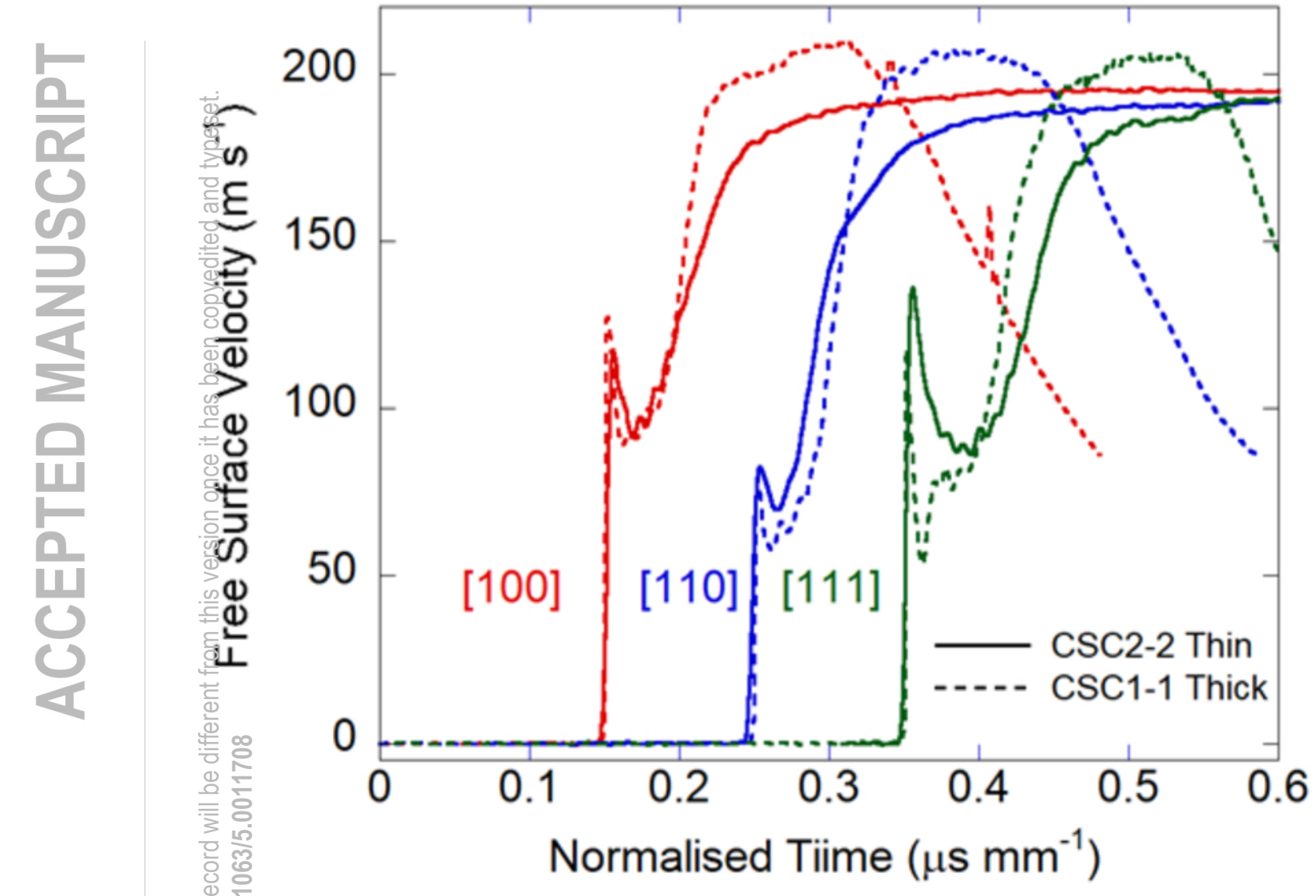

a) lower pressure shots at $6 \mathrm{GPa}$

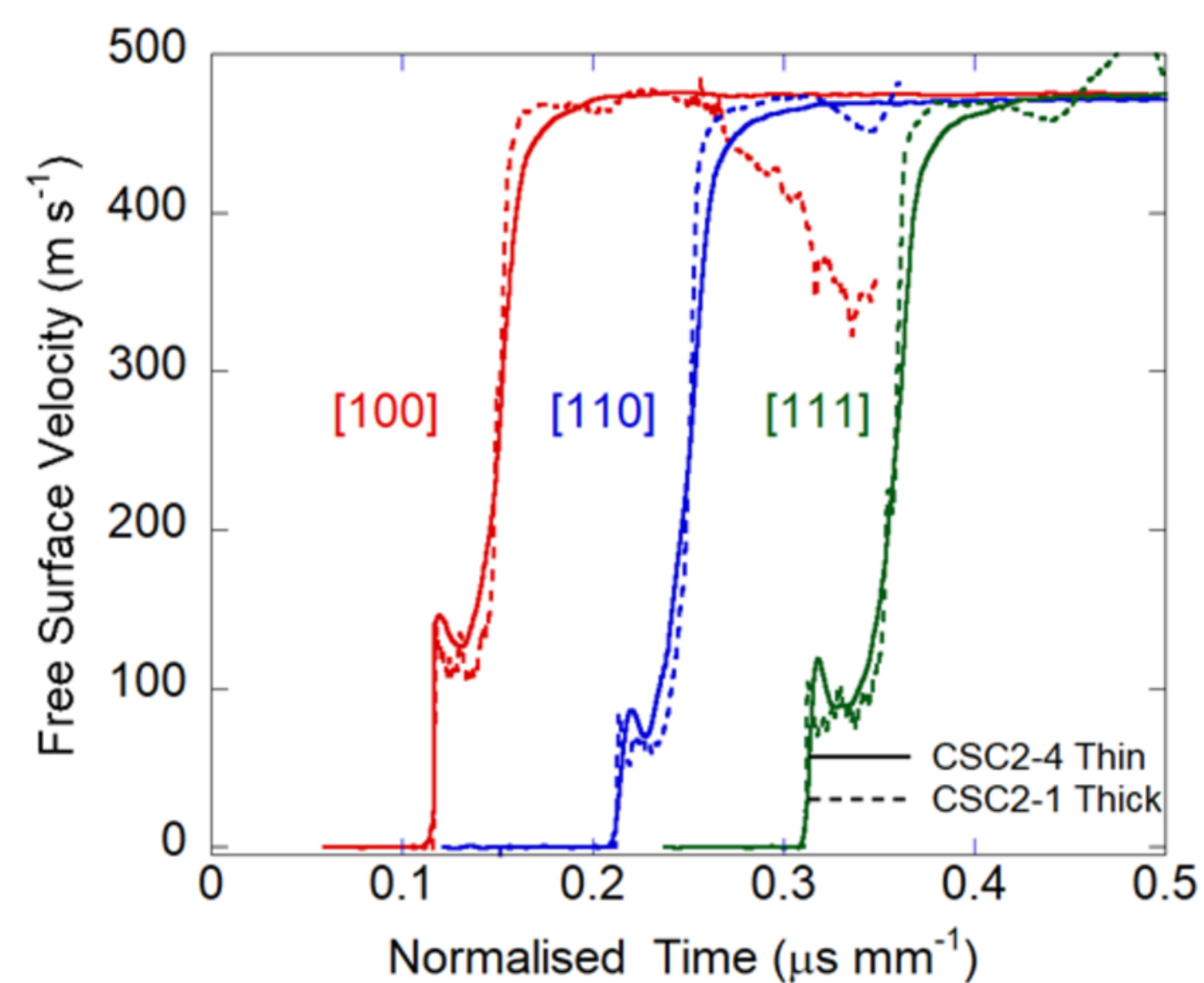

b) high pressure shot at $15 \mathrm{GPa}$

Figure 7. Comparison of thickness normalised traces (Thin - ca. $0.8 \mathrm{~mm}$ and Thick ca. $4 \mathrm{~mm}$ ). a) lower pressure shots at $6 \mathrm{GPa}, \mathrm{b}$ ) high pressure shot at $15 \mathrm{GPa}$. 